\title{
1 Topographic and stochastic influences on pāhoehoe lava lobe emplacement
}

3 Christopher W. Hamilton ${ }^{1,2}$, Lori S. Glaze ${ }^{1}$, Mike R. James ${ }^{3}$, and Stephen M. Baloga ${ }^{4}$

$4{ }^{1}$ Planetary Geodynamics Laboratory, NASA Goddard Space Flight Center, Greenbelt, 5 MD, 20771, USA, christopher.hamilton@nasa.gov.

$6 \quad{ }^{2}$ Department of Astronomy, University of Maryland, College Park, MD, USA.

$7 \quad{ }^{3}$ Lancaster Environment Centre, Lancaster University, Lancaster, UK.

$8{ }^{4}$ Proxemy Research, Laytonsville, MD, USA

10 Abstract

11 A detailed understanding of pāhoehoe emplacement is necessary for developing

12 accurate models of flow field development, assessing hazards, and interpreting the

13 significance of lava morphology on Earth and other planetary surfaces. Active pāhoehoe

14 lobes on Kîlauea Volcano, Hawai'i, were examined on 21-26 February 2006 using

15 oblique time-series stereo-photogrammetry and differential global positioning system

16 (DGPS) measurements. During this time, the local discharge rate for peripheral lava lobes

17 was generally constant at $0.0061 \pm 0.0019 \mathrm{~m}^{3} / \mathrm{s}$, but the areal coverage rate of the lobes

18 exhibited a periodic increase every $4.13 \pm 0.64$ minutes. This periodicity is attributed to

19 the time required for the pressure within the liquid lava core to exceed the cooling-

20 induced strength of its margins. The pāhoehoe flow advanced through a series of down-

21 slope and cross-slope breakouts, which began as $\sim 0.2 \mathrm{~m}$-thick units (i.e., toes) that

22 coalesced and inflated to become approximately meter-thick lobes. The lobes were

23 thickest above the lowest points of the initial topography and above shallow to reverse- 
24 facing slopes, defined relative to the local flow direction. The flow path was typically

25 controlled by high-standing topography, with the zone directly adjacent to the final lobe

26 margin having an average relief that was a few centimeters higher than the lava-

27 inundated region. This suggests that toe-scale topography can, at least temporarily, exert

28 strong controls on pāhoehoe flow paths by impeding the lateral spreading of the lobe.

29 Observed cycles of enhanced areal spreading and inflated lobe morphology are also

30 explored using a model that considers the statistical likelihood of sequential breakouts

31 from active flow margins and the effects of topographic barriers.

\section{1. Introduction}

34 Basalt is the most common rock type on the surface of terrestrial bodies

35 throughout the solar system and — by total volume and areal coverage — pāhoehoe flows

36 are the most abundant form of basaltic lava in subaerial and submarine environments on

37 Earth (Self et al., 1994, 1998). Pāhoehoe flow fields are composed of flows, lobes, and

38 toes, which represent a continuum of lava emplacement scales, with toes being the

39 smallest elements. Pāhoehoe flows commonly advance as toes break out along lobe

40 margins (Hon et al., 1994; Crown and Baloga, 1999; Hoblitt et al., 2012). These new toes

41 quickly cool and develop a rheological gradient that includes an inferred three-part

42 structure composed of a brittle outer crust, underlying viscoelastic layer, and inner molten

43 core (Hon et al., 1994). As toes develop sufficient strength to retain incoming lava, they

44 can pressurize, coalesce, and inflate to form lobes that are interconnected with other

45 portions of the flow through internal fluid pathways (Walker, 1991, 2009). The evolution

46 of these pathways can vary considerably (Kauahikaua et al., 1998), but the initial 
47 emplacement of pāhoehoe flow fronts can influence the subsequent development of the

48 flow. Consequently, a detailed understanding of processes operating on the scale of toes

49 and lobes can provide important information for modeling aspects of flow field

50 development, assessing hazards, and interpreting the significance of lava flow

51 morphology on Earth and other planetary bodies (Peitersen and Crown, 2000; Byrnes and

52 Crown, 2001).

53 Hon et al. (1994) suggest that "microtopography" (i.e., tens of centimeters relief),

54 herein termed "toe-scale topography", can strongly affect the emplacement of pāhoehoe

55 lava flows that reach a final inflated thickness of several meters. Previous studies have

56 attempted to determine the relationship between topography and pāhoehoe emplacement

57 (Crown and Balgoa, 1999; Peitersen and Crown, 2000; Byrnes and Crown, 2001), but

58 these studies have been unable to quantify the effects of toe-scale topography at the flow

59 front due to data resolution limitations. Here, oblique digital photogrammetry and

60 Differential Global Positioning System (DGPS) measurements are combined to quantify

61 key physical parameters involved in pāhoehoe flow advance through development of toes

62 and lobes, which constitute the fundamental building blocks of all pāhoehoe flows

63 (Walker, 1991; Self et al., 1996, 1998; Thordarson and Self, 1998). These field

64 observations are also used to inform and constrain a new stochastic model that describes

65 pāhoehoe lobe emplacement in terms of a balance between random and non-random

66 processes.

67

68 2. Background 
Pāhoehoe flow fields exhibit a multitude of branching events at several scales

70 (Crown and Baloga, 1999) and include self-similar morphologies (Bruno et al., 1994) that

71 enable local observations to be used to understand larger aspects of flow fields and their

72 emplacement. However, these patterns are complicated and irregular because of the

73 influence of stochastic processes operating on multiple scales (Kilburn, 1996). This

74 makes it important to identify the scales over which recurring processes and structures

75 combine to form the overall pattern of a pāhoehoe flow field. Understanding how

76 eruption parameters, deterministic factors, and random influences affect the emplacement

77 and modification of pāhoehoe flows, also makes it possible to develop improved

78 probabilistic models to describe likely patterns of flow growth (Glaze and Baloga, 2013).

79 This study examines active pāhoehoe lava lobes on Kīlauea Volcano, Hawai ‘i, to

80 characterize the effects of toe-scale topography on flow emplacement and identify key

81 parameters needed to model statistical aspects of the process.

82 Pāhoehoe flows grow through a combination of areal spreading and inflation, with

83 new toes breaking out along lobe margins and quickly cooling by radiation (Hon et al.,

84 1994; Keszthelyi and Denlinger, 1996; Harris et al., 2007a, 2013). Once a thin skin

85 develops on the surface of the new toes, cooling becomes increasingly dominated by

86 conduction (Castruccio et al., 2013). The crust also helps to retain incoming lava, which

87 slows the advance of the new toes as their internal pressure decreases relative to the

88 increasing confining strength of the growing crust (Hon et al., 1994). Given a constant

89 influx of lava, this leads to a reduction in the areal coverage rate of the toes and an

90 increase in the rate of inflation. Inflation will then continue to dominate the emplacement

91 process until the internal pressurization of the lobe reaches a threshold required to rupture 
92 the flow margins and initiate a new cycle of enhanced areal spreading (Hoblitt et al.,

93 2012).

94 Within an active pāhoehoe flow, internal connections between numerous lobes

95 can form extensive lava pathways (Kauahikaua et al., 1998). Preferred pathways within

96 these lava networks tend to concentrate in existing topographic lows and may develop

97 into a tube-system as the surrounding flow cools and stagnates. This allows pāhoehoe

98 flows to advance great distances by transporting lava to the flow front through thermally

99 insulated pathways that can reduce cooling rates to only $0.5-1.0^{\circ} \mathrm{C} / \mathrm{km}$ (Helz at al.,

100 1991). As lava is distributed from a master pathway into peripheral lobes and toes, the

101 local discharge rates will progressively decrease with each branch in the system. Local

102 discharge rates may therefore be constant over short periods of time (Hon et al., 1994),

103 but are expected to evolve as the lobes at the former flow front are incorporated into the

104 growing body of the lava transport system. In this study, lobes along the periphery of a

105 low discharge pāhoehoe flow are examined to explore flow front emplacement processes

106 and inflation.

107

108 3. Study Area

109 The Prince Kūhiō Kalaniana'ole (PKK) flow was erupted from $\mathrm{Pu}^{\prime} \mathrm{u}$ ' $\overline{\mathrm{O}}^{`}$ ō on

110 Kīlauea Volcano, Hawai' ${ }^{i}$, from March 2004 to June 2007 (Fig. 1). Active margins along

111 the flow were examined in the field between 21-26 February 2006. During this time, lava

112 from $\mathrm{Pu}^{`} \mathrm{u}{ }^{\prime} \overline{\mathrm{O}}^{`} \overline{\mathrm{o}}$ was primarily transferred though an established tube system that reached

113 the ocean (Koeppen et al., 2013). However, during February 2006, the master tube-

114 system also fed a series of small surface flows located $\sim 7 \mathrm{~km}$ south of $\mathrm{Pu}^{`} \mathrm{u}{ }^{`}{ }^{`}{ }^{`} \bar{o}$. Harris 
115 et al. (2007a) referred to this portion of the PKK flow as the "Hook flow". Field

116 observations and thermal imagery were used to establish that this flow exhibited

117 breakouts of S-type pāhoehoe (Wilmoth and Walker, 1993) from three small flows on 21

118 February. However, by 23 February, the activity had dwindled to the distal margin of just

119 one flow. Waning activity was also evidenced by a decrease in maximum core

120 temperature from $1141^{\circ} \mathrm{C}$ on 21 February, to $1131^{\circ} \mathrm{C}$ on 23 February, and a decrease in

121 areal coverage rate from $\sim 0.22 \mathrm{~m}^{2} / \mathrm{s}$ on February 22 to $\sim 0.03 \mathrm{~m}^{2} / \mathrm{s}$ on 23 February (Harris

122 et al., 2007a). Additionally, there was a corresponding decrease in discharge rate feeding

123 small surface flows, from $\sim 0.14 \mathrm{~m}^{3} / \mathrm{s}$ on February 22 to $\sim 0.03 \mathrm{~m}^{3} / \mathrm{s}$ on 23 February

124 (Harris et al., 2007a). These surface flows stagnated on February 24. Measurements

125 reported in this study were made contemporaneously with the observations of Harris et al.

126 (2007a), who used thermal-image chronometry to establish broad relations among

127 cooling, discharge rate, and areal coverage rates for the whole flow.

128 To place the local discharge rates discussed within this study into a broader

129 context, the $\mathrm{Pu}^{\prime} \mathrm{u}$ ' $\overline{\mathrm{O}}^{`} \overline{\mathrm{o}}-\mathrm{Kupaianaha}$ eruption began erupting in Kīlauea Volcano's East

130 Rift Zone (ERZ) in January 3, 1983, and between 1983 and 2002 its time-averaged

131 discharge rate (Harris et al., 2007b) was $\sim 3.81 \mathrm{~m}^{3} / \mathrm{s}$ dense-rock-equivalent lava (Heliker

132 and Mattox, 2003). However, the $\mathrm{Pu}^{\prime} \mathrm{u}{ }^{‘} \overline{\mathrm{O}}^{`} \overline{\mathrm{o}}-\mathrm{K}$-Kapaianaha eruption has undergone

133 numerous changes throughout its history (Heliker and Mattox, 2003) and in 2003-2007

134 the magma supply rate to the ERZ increased significantly during a mantle-derived surge

135 to Kîlauea Volcano (Poland et al., 2012). During this time, the magma supply to Kîlauea

136 Volcano increased by a factor of two (Poland et al., 2012). By 2005 the supply rate to the

137 ERZ increased to $\sim 5.11 \mathrm{~m}^{3} / \mathrm{s}$ (Poland et al., 2012) and so at the time of the field campaign 
138 in February 2006, effusion rates from $\mathrm{Pu}^{‘}{ }^{\prime}{ }^{`} \overline{\mathrm{O}}^{`} \bar{o}$ were probably higher than the long-term

139 average. Tilt meter records from the Hawaiian Volcano Observatory's Pu'u ' $\bar{O}^{‘}$ ô cone

140 station also show that there was an oscillatory pattern of inflation and deflation between

141 21-26 February 2006 (Orr, 2011). This pattern began with an inflation event on 21

142 February, which was followed by gradual deflation over the next five days through a

143 series of smaller tilt cycles (Tim Orr, personal communication, 2013). Orr (2011) showed

144 that these tilt cycles were associated with fluctuations in lava discharge through the tube

145 system and may have contributed to the observed breakouts from the master tube.

146 Discharge rates associated with the small surface flows examined within this study were

147 therefore much lower than for the concurrently active PKK tube and the eruption as a 148 whole.

\section{4. Methods of Digital Terrain Modeling}

151 To quantify aspects of the pāhoehoe emplacement processes, two complementary 152 methods were employed. First, time-series oblique stereo-imaging and photogrammetry 153 (Robson and James, 2007) were used to determine the changing geometric properties of 154 an active lava lobe, herein referred to as Lobe A. Second, Differential Global Positioning

155 System (DGPS) measurements of topography before and after the emplacement of a

156 second pāhoehoe lobe (Lobe B) were used to assess the relationship between initial

157 topography and final lobe morphology. Lobes A and B were located along the same lava

158 pathway system, with Lobe B located $\sim 10$ m directly down-flow of Lobe A.

159 Time series stereo-image pairs of Lobe A were acquired on 23 February using

160 two synchronized tripod-mounted digital Single Lens Reflex cameras (6 mega-pixel 
161 Canon EOS 300D), which collected image pairs every minute over a duration of 35

162 minutes (Robson and James, 2007). The cameras were mounted approximately one meter

163 apart and had pre-calibrated, fixed-focus $28 \mathrm{~mm}$ lenses. Photogrammetric control was

164 provided using spherical targets $(0.25 \mathrm{~mm}$ in diameter $)$ with positions determined by

165 DGPS measurements. The analysis was carried out using Vision Measurement System

166 (Robson and Shortis, http://www.geomsoft.com) with image matching by the GOTCHA

167 dense matching algorithm (Gruen, 1985; Day and Muller, 1989; Otto and Chau, 1989). A

168 typical stereopair provided topographic point cloud data with positional precisions of 25 ,

16965 and $20 \mathrm{~mm}$ in easting $(x)$, northing $(y)$, and elevation $(z)$, respectively. To quantify

170 surface changes, these point cloud data were gridded in Surfer using a Kriging algorithm

171 over a $0.1 \mathrm{~m} /$ pixel $x-y$ grid. The data were then imported into ArcGIS.

172 For Lobe B, $x, y$, and $z$ coordinates for topographic surfaces were acquired before

173 (23 February) and after lava emplacement. Post-emplacement surveys were performed on

174 24-26 February; however, no changes were observed after 24 February and so data from

175 these three surveys were combined together. Data were collected at a sampling rate of 0.5

176 seconds using two Ashtech Z-Xtreme DGPS receivers-one operating in kinematic mode

177 and the other as a static base-station. These data were post-processed using Ashtech

178 Solutions 2.60 with differential, L1/L2 (1575.42 MHz/1227.60 MHz) frequency

179 correction for ionospheric delay error, and International Global Navigation Satellite

180 System Service Standard Product 3 precise orbit file corrections. Resulting data points

181 were filtered to remove measurements with more than $0.05 \mathrm{~m}$ residual accuracy error. On

182 volcanic terrains, Hamilton et al. (2010) estimate the vertical precision of single traverse

183 kinematic DGPS surveys to be $\pm 0.08 \mathrm{~m}$, and double traverses being $\pm 0.06 \mathrm{~m}$, with 
184 horizontal precision being better than the vertical measurements. Most gridded cells in

185 this dataset contain multiple DGPS observations and should have a vertical precision of

$186 \pm 0.06 \mathrm{~m}$. The resulting datasets for the initial and final topography include 14,618 and

18720,585 records, respectively. To avoid spatial aliasing and to eliminate redundant data,

188 the BLOCKMODE function in Generic Mapping Tools (GMT; Wessel and Smith, 1991)

189 was used to average $z$ within each pixel. Filtered $x, y$, and $z$, data were then interpolated

190 using NEARNEIGHBOR in GMT to form a $0.1 \mathrm{~m} /$ pixel $x-y$ grid.

\section{5. Time Series Observations of Pāhoehoe Lobe Emplacement}

193 Stereogrammetric point clouds and interpolated Digital Terrain Models (DTMs)

194 were used to identify and digitize the active margins of Lobe A at 1-minute intervals (Fig.

195 2). These areal spreading maps show that the lava lobe grew by a series of breakouts that

196 broadly fit into two categories: narrow (0.2-0.6 m-wide) toes that grew preferentially

197 down-slope and broad (1.4-3.5 m-wide) breakouts that formed along the sides of the

198 lobe, nearly perpendicular to the down flow axis (Figs. 3 and 4). Initial toe thicknesses

199 were typically $\sim 0.2 \mathrm{~m}$ and, during the 35 minute period of observation, they inflated to a

200 maximum thickness of $\sim 1.1 \mathrm{~m}$, with most toes inflating to half their final thickness within

20110 minutes. Within the first minute of emplacement toes generally extended $\sim 0.2 \mathrm{~m}$, with

202 a range of 0.05 to $0.55 \mathrm{~m}$. After 28 minutes, the active flow margin began to exit the field

203 of view of the stereo cameras and toe lengths could not be accurately constrained.

204 The mean local discharge rate measured at Lobe A over the first 19 minutes was

$2050.0061 \pm 0.0019 \mathrm{~m}^{3} / \mathrm{s}(N=19$, Fig. 5a). Note that all uncertainties in this study are

206 reported at 1 standard deviation, $\sigma$, unless otherwise noted. Standard deviation describes 
207 how much variation there is from the mean, whereas standard error on the mean, $\sigma_{\mu}$,

208 provides a measure of how well the mean is known based on the number of data points,

$209 N$, used in the calculation. We therefore provide $N$ as well as $\sigma$ to enable the calculation

210 of $\sigma_{\mu}=\sigma / \sqrt{N}$. After 35 minutes, the lobe covered a new area of $11.7 \mathrm{~m}^{2}$ and achieved a

211 cumulative volume of $10.4 \mathrm{~m}^{3}$.

212 This local discharge rate was remarkably constant during the observation period,

213 except for the interval between 19 and 24 minutes, when it decreased by nearly a factor

214 of four. During this interval, the lobe experienced little inflation and generally lower than

215 average areal spreading rates (Fig. 5a), which may have been due to breakouts occurring

216 outside the field of view. At 24 minutes, the local discharge rate of $0.0061 \mathrm{~m}^{3} / \mathrm{s}$ resumed,

217 but after 28 minutes, the measured rate of volume change gradually decreased as the

218 active flow front began to exit the field of view of the stereo-cameras. The mean areal

219 coverage rate was $0.0055 \pm 0.0038 \mathrm{~m}^{2} / \mathrm{s}(N=35)$. The areal coverage exhibits a

220 periodicity with peaks $\sim 3$ times greater than the mean (Fig. $5 b$ ) and a period of $4.13 \pm$

2210.64 minutes $(N=8)$. During each cycle of areal growth (measured from trough to trough

222 in areal coverage rates shown in Fig. 5b), the lobe covers a new area of $1.59 \pm 0.28 \mathrm{~m}^{2}(\mathrm{~N}$ $223=7)$.

224 Excess volume refers to the portion of a lava lobe that is not directly associated 225 with its initial areal expansion. In this case, excess volume is defined as the volume

226 change in the field of view per minute minus the change in area during that minute

227 multiplied by the typical initial thickness of the new breakouts. The typical thickness of

228 new breakouts from Lobe A was $\sim 0.2 \mathrm{~m}$, but may vary for other flows - generally scaling

229 with local discharge rate (Self et al., 1998). Excess volume changes for Lobe A appears 
230 to be weakly anti-correlated with its areal spreading rate. However, to quantify the degree

231 of anti-correlation, the cross-correlation coefficient was calculated between the areal

232 growth and excess volume. The correlation analysis was restricted to the first 19 minutes

233 of observation when the volume flow rate feeding the lobe was relatively constant. The

234 areal growth rate during this 19 minute period exhibits a slight overall increase over time

235 (slope $=0.013 \mathrm{~m}^{2} /$ minute and intercept $=0.206 \mathrm{~m}^{2} /$ minute), and therefore the trend was

236 removed prior to analysis. After trend removal, the cross correlation coefficient, at lag =

2370 (the measure of direct anti-correlation) is -0.22 . The negative sign of this statistic

238 indicates anti-correlation; however, the magnitude is well within the $90 \%$ confidence

239 interval $( \pm 0.34)$ indicating that the anti-correlation is very weak and not statistically

240 significant at this level. This suggests that there may be a trade-off between areal

241 spreading and inflation given an approximately constant lava supply, but that the

242 relationship may be complicated by other factors. See Section 7.2 for further discussion.

244 6. Lava Thickness, Inflation, and the Effects of Topographic Relief on Pāhoehoe

245 Lobe Emplacement

246 Topographic maps of the terrain before and after the emplacement of Lobe B are

247 shown in Figure 6. Lava covered $111.83 \mathrm{~m}^{2}$ within the DGPS survey region, with a total

248 lobe volume of $59.45 \mathrm{~m}^{3}$. Forward Looking Infrared Radiometer (FLIR) measurements of

249 the flow at 06:00 on 24 February 2006, revealed no anomalously hot pixels within the

250 study region, which indicates that the flow terminated at least 5 hours before (Harris et

251 al., 2007). Based on the time of the last field observations on 23 February, this constrains

252 the emplacement duration to $<8$ hours. If the mean areal coverage and discharge rates 
253 were similar for Lobes A and B, then the emplacement duration of Lobe B was likely 254 between 2.6 and 5.2 hours.

255 Using the before and after DTMs (Figs. 6a and b), topographic profiles have been 256 extracted down-slope (Fig. 7a) and cross-slope (Fig. 7b). The lava entered the study 257 region from the north and the lobe grew to a length of $\sim 18 \mathrm{~m}$ and a maximum width of

$2589.1 \mathrm{~m}$. However, the distal part of the flow focused into a $4.3 \mathrm{~m}$-wide topographic

259 constriction before being bifurcated by a $1.0 \mathrm{~m}$-high topographic obstacle into two

260 smaller lobes that were $2.4 \mathrm{~m}$ and $4.0 \mathrm{~m}$-wide. The profiles show that inflation of the lava

261 tended to topographically invert the landscape, with the thickest portions of the lobe

262 developing above topographic depressions and shallow to reverse-facing slopes, defined

263 relative to the local flow direction. Thus, apparent barriers to the spreading of the flow

264 are typically much smaller than the maximum height of the lobe and the thicker portions

265 of the lobe appear confined by the thinner peripheral parts of the flow.

266 The thickness distribution of Lobe B (Fig. 6c) above the existing surface was

267 calculated by taking the simple difference between the final and initial topography. This

268 yields a mean lobe thickness of $0.57 \pm 0.24 \mathrm{~m}$, with a maximum of $1.21 \mathrm{~m}$. However,

269 simple topographic difference overestimates inflation because lobes are initially

270 emplaced as toes with an initial thickness. Additionally, lava had to fill small closed

271 depressions before thickening above the surrounding topography.

272 To account for the infilling of small topographic depressions, a new initial surface

273 was created by smoothing the initial topography in a process that is analogous to tightly

274 stretching a rubber sheet through the data. The smoothed surface was created using the

275 GMT function SURFACE, which interpolates a grid using continuous curvature splines 
276 in tension (Smith and Wessel, 1990). Specifically, SURFACE applies the Laplace

277 transform $(L)$ to the initial topography $(z)$ :

278

$$
(1-T) L \times(L(\mathrm{z}))+T \times L(z)=0 .
$$

279 Varying the tension factor $T$ between 1 (i.e., the harmonic surface solution) and 0

280 (i.e., the minimum curvature solution) enables this data interpolation method to smooth

281 the initial surface to different degrees. For instance, a grid produced with high tension ( $T$

$282 \rightarrow 1$ ) will suppress local maxima and minima by fitting an increasingly taut surface

283 between the data constraints, whereas applying a looser tension factor $(T \rightarrow 0)$ will

284 produce a smooth polynomial function analogous to a flexed elastic plate that is anchored

285 by the data (Smith and Wessel, 1990).

286 To constrain the inflated thickness of Lobe B, a smoothed local datum was fit to

287 the initial topography using a $T$-value of 1 . This removes high frequency oscillations in

288 the topography, while preserving the overall shape of the terrain. Subtracting this surface

289 from the final topography isolates the thickness of lava above the local datum and

290 provides a better proxy for inflation than the simple difference map because it reduces the

291 thickness contributions due to small basin infilling. Using this method, the mean

292 thickness due to inflation was $0.34 \pm 0.21 \mathrm{~m}(N=9614)$, with a maximum of $1.00 \mathrm{~m}$ (Fig.

293 6d).

294 To isolate local relief within the initial topography, a second interpolated surface

295 was created using Eq. (1) with $T=0.25$. A loose tension factor of $T=0.25$ is

296 recommended for low-tension interpolations to suppress extraneous oscillations (i.e.,

297 minima and maxima) that can otherwise be generated within the $T=0$ (i.e., end-member

298 minimum curvature) solution (Wessel and Smith, http://gmt.soest.hawaii.edu/). The new 
surface preserves more variations in the initial topography than the harmonic surface

300 solution $(T=1)$ and was subtracted from the original initial topography to isolate high

301 frequency changes in elevation (i.e., relief) above and below a new local datum centered

302 on $0 \mathrm{~m}$.

303 In the lava inundated region, the distribution of initial relief is unimodal with a

304 mean of $-0.02 \pm 0.07 \mathrm{~m}(N=9614$ pixels; Fig. 8). For comparison, a 1-pixel buffer region

305 was also defined around the outer extent of the lobe and, in this buffer region, the

306 frequency distribution of relief had a mean of $0.00 \pm 0.07 \mathrm{~m}(N=499$ pixels $)$. However,

307 relative to the lava inundated region, there are more pixels with a relief of 0.03 to $0.09 \mathrm{~m}$

308 and fewer pixels with a relief of -0.09 to $-0.03 \mathrm{~m}$ (Fig. 8). This implies that there are

309 systematically more high relief pixels bounding the pāhoehoe lava lobe than in the region

310 that was inundated. Consequently, positive relief on the order of only a few centimeters

311 may exert an important influence on bounding the extent of low-effusion-rate pāhoehoe

312 flows.

313 Toe-scale topography (i.e., on the order of centimeters in this case) appears to

314 influence the areal spreading of pāhoehoe lobes by blocking peripheral toes, which may

315 then stagnate and help confine the interior portions of the flow. If the interior of the flow

316 continues to be supplied by lava it may then inflate above the height of the surrounding

317 barriers, thereby topographically inverting the landscape. Barriers to flow may therefore

318 be much less than the final inflated thickness of a lobe. Based on observations of Lobe B,

319 relief that is at least $15 \%$ of a toe's initial thickness may be significant in terms of

320 affecting the path of low-discharge pāhoehoe lava lobes, but given sample-size-

321 dependent restrictions on the optimum bin-size for the data (Stuges, 1926; Doane, 1976), 
322 influences of even smaller variations in topography cannot be precluded. Obstacle

323 heights affecting the path of higher local discharge rate flows may similarly scale with

324 initial toe height.

325

326 7. Stochastic Modeling of Pāhoehoe Lobe Emplacement

327 7.1. Overview of the Model

328 Random effects strongly influence processes of pāhoehoe flow growth and pose a

329 fundamental difficulty in developing models for their emplacement (Hon et al. 1994;

330 Thordarson and Self, 1998; Keszthelyi et al., 1999; Crown and Baloga, 1999). Glaze and

331 Baloga (2013) have recently developed a new simulation approach for modeling

332 pāhoehoe emplacement that builds on the ideas presented in Baloga and Glaze (2003).

333 This model is based on (1) conservation of lava volume and (2) prescribed stochastic

334 rules for lava movements within a pāhoehoe lobe. This approach differs significantly

335 from other models that treat lava emplacement as a gravity-driven viscous fluid flow on

336 an inclined plane (e.g., Danes, 1972; Hulme, 1974; Baloga and Pieri, 1986; Baloga, 1987;

337 Crisp and Baloga, 1990; Harris and Rowland, 2001; Rowland et al., 2004; Baloga and

338 Glaze, 2008). The Glaze and Baloga (2013) model simulates the 3-Dimensional shape for

339 pāhoehoe lobes as they evolve in time, subject to a wide variety of ambient and internal

340 conditions and processes. Here, the new model is used to explore the effects of inflation

341 on pāhoehoe lobes analogous to Lobes A and B.

342 The fundamental building block of the Glaze and Baloga (2013) model is the lava

343 "parcel". A "parcel" of lava is defined here as a volumetric unit sampled from a

344 probability distribution of lava volumes that typically construct a pāhoehoe lobe. Thus 
345 the smallest toe observed on the surface or along the margins of a pāhoehoe lobe

346 represents a lava parcel volume from the small end of the distribution. However, larger

347 toes may either represent a larger parcel volume, or may be comprised of multiple

348 parcels.

349 A parcel is observable as a "toe" when it is permanently affixed at the surface or

350 margin of a lobe. In the Glaze and Baloga (2013) model, lava parcels originate from a

351 source region and are transported through fluid internal pathways. For the purposes of

352 discussion here, the model assumes a constant parcel size for all parcels. Crown and

353 Baloga (1999) measured dimensions of hundreds of toes and their mean thickness is very

354 well constrained at $\sim 0.20 \mathrm{~cm},(0.19 \pm 0.08 \mathrm{~m}, N=448)$. Based on the geometric mean toe

355 sizes measured by Crown and Baloga (1999), the parcel volume is assumed to be $0.09 \mathrm{~m}^{3}$

356 (Glaze and Baloga, 2013). Assuming a square $x-y$ grid and a typical parcel thickness of

$3570.2 \mathrm{~m}$-comparable to the observed initial thickness of toes in our study area - the

358 corresponding cell spacing is $0.67 \mathrm{~m}$, with a parcel area of $0.45 \mathrm{~m}^{2}$.

359 The Glaze and Baloga (2013) random simulation model begins with an initial

360 source region (a single point, linear source, etc.), a constant supply of lava (i.e., one

361 parcel per time step), and probabilistic rules governing where each parcel will be

362 transferred and allocated. For example, in the most basic scenario of complete

363 randomness, two random choices are made for each breakout. First, a parcel is randomly

364 selected to be the source for the next parcel transfer. Second, a random selection is made

365 to determine the orientation of the new parcel transfer relative to its source (i.e., North,

366 South, East, or West). In the purely random case, every face of every parcel has an equal

367 probability of being the source for the next parcel transfer. As various factors that 
368 influence emplacement are examined (e.g., barriers, slope, etc.), different probabilistic

369 rules are applied that determine where and when each parcel will be transferred.

\section{7.2. Model Simulations of Areal Growth}

$372 \quad$ Figure 9a shows a typical example of a completely random simulation involving

373500 parcels. In this simulation, each transfer location and direction is chosen at random.

374 Figure 10a (solid line) shows the corresponding cumulative area as a function of time

375 step. However, Glaze and Baloga (2013) showed that topographic profiles of pahoehoe

376 lobes are more consistent with simulations that include sequential breakouts at the

377 margin. In this case, the momentum of new parcels breaking out from a lobe margin

378 results in an increased probability that the next parcel will be transferred from the most

379 recent parcel in the same direction. Figure $9 \mathrm{~b}$ shows the influence of allowing sequential

380 breakouts at the lobe margin on lobe morphology. Specifically, every time a new parcel is

381 transferred to the margin (increasing the lobe area) probabilistic rules are used to

382 determine whether 0,1 , or 2 extra parcels will be added at that location. For the

383 simulation shown in Figure 9b, the probability of 0 additional parcels is $P(0)=0.25$, of 1

384 additional parcel being added is $P(1)=0.25$, and of 2 additional parcels is $P(2)=0.5$. As

385 expected, the cumulative area of the simulation that includes sequential breakouts at the

386 margin rapidly diverges from the purely random simulation (Fig. 10a), exhibiting a

387 steeper gradient and overall greater cumulative area. Although a general trend in the areal

388 growth ( $\mathrm{m}^{2}$ per time step) is evident in both simulations shown in Figure 10a, the curves

389 are irregular with periods where the area increases rapidly and periods where the area

390 does not change at all. Also as expected, the rate of overall areal growth tapers off over 
391 time as the number of available lava transfer locations along the margins decreases

392 relative to the total area of the lobe.

393 The Glaze and Baloga (2013) simulation approach explicitly requires that lava

394 parcels will either expand the area of the flow or contribute to inflation if they are

395 allocated to the flow interior. This naturally results in a trade-off between areal growth

396 and interior lobe inflation similar to the pattern observed during the emplacement of Lobe

397 A. The natural periodicity of the areal growth rate in the simulated lobes is illustrated by

398 the solid line in Figure 10b. Also shown in Figure 10b is the excess volume, which was

399 defined in Section 5 as the volume in addition to what is directly associated with the

400 change in lobe area because all breakouts will be emplaced with some initial thickness.

401 For the simulated data, the definition of excess volume results in a periodic behavior that

402 exactly mirrors the areal growth (i.e., perfect anti-correlation). This suggests that the

403 weak anti-correlation shown in Figure 5b may be relevant, but also indicates that other

404 processes are present in the field that have not yet been accounted for by the model. Also

405 in the field example, there was a period of anomalously low average lava flux between

406 20-23 minutes, which coincided with a period of negative excess volume change. This

407 indicates that areal spreading can also be accommodated by the depletion of lava stored

408 within the parent lobe, rather than always being related to a simple balance between

409 pressurization and confining strength under conditions of constant lava supply. Future

410 studies would therefore benefit from longer time-series observations of multiple active

411 lava lobes to further explore the statistical significance of the relationship between areal

412 spreading and inflation. 


\subsection{Comparisons Between Model Simulations and Observations}

415 Given the measured volume of Lobe A and typical parcel volume of $0.09 \mathrm{~m}^{3}$,

416 Lobe A would include $\sim 117$ parcels. The simulation of a lobe composed of 117 parcels

417 begins with a $1 \times 7$ cell linear source region trending East-West (depicted as the gray

418 shaded region in Figure 11a crossing through the mid-point of the array). This source

419 region, with one parcel in each of the seven cells, is approximately equivalent to the

420 initial length of Lobe A (i.e., 4.69 m; see Fig. 4a). The model also includes two parallel

421 barriers located at \pm 3 cells along the North-South axis. The barriers are considered

422 transitional zones in which the advancing lava enters, but becomes blocked, thereby

423 reflecting the lava parcel back toward the interior of the flow. The distance between these

424 barriers is $4.69 \mathrm{~m}$ (including the barrier cells as well), which corresponds to the

425 topographically-bounded maximum width of Lobe A. The probabilities of sequentially

426 adding 0,1 , or 2 extra parcels from an existing flow margin are $P(0)=P(1)=0.25$, and

$427 \quad P(2)=0.5$.

428 One cannot expect any specific realization of the stochastic model to exactly

429 reproduce the morphology of an observed lava lobe, but characteristics of the simulated

430 lobes are broadly consistent with the morphology of Lobe A. Figure 11b shows examples

431 of topographic profiles taken perpendicular to the flow direction through the simulated

432 lobes averaged over 10, 20,30, and 60 realizations. These examples demonstrate that

433 there are stochastic variations between simulations, but also persistent morphological

434 characteristics. For example, the simulated lobes are thickest in the middle (i.e., along the

435 axis of the linear source region) with maximum heights that are consistent with those

436 observed for Lobe A. The models also exhibit the effects of lava confinement along lobe 
437 margins due to lava parcels being reflected back toward the interior of the flow. Plan

438 views of the simulated lobes (e.g., Figs. 9a and 9b) also show irregular margins and

439 thickness variations that are typical of inflated pāhoehoe lobes.

\section{8. Discussion}

\section{8.1. Relationships between Pāhoehoe Breakouts and Inflation}

443 Pāhoehoe breakouts will be emplaced with some initial thickness and then grow

444 through a process of inflation. This inflation process includes two dominant components:

445 thickening of the molten core and thickening of the crust (Hon et al., 1994), with the crust

446 consisting of both a brittle outer layer and underlying viscoelastic layer. After an initial

447 chilled margin forms around a new toe, it will retain incoming lava and inflate as its

448 molten core thickens to equalize the pressure with other connected portions of the fluid

449 lava pathway. During the early stages of emplacement, the rate of core thickening will

450 greatly exceed the rate of crustal thickening (Hon et al., 1994), but as the fluid interior

451 achieves its equilibrium thickness, inflation will be increasingly dominated by the process

452 of crustal growth (Cashman and Kauahikaua, 1997).

453 Two conditions must be met for the upper crust to continue to accrete new

454 material and contribute to inflation. First, there must be a continuous influx of new lava

455 through the molten core and, second, there must be physical coupling of the molten core

456 to the upper crust (Kauahikaua et al., 1998). If the flow of lava through the core stagnates

457 then the lava will cool in situ and will not increase the flow's total thickness.

458 Additionally, if the molten core partially drains and decouples from the upper crust then

459 new material will not be added to the base of the surface layer and the crust may even 
460 subside and "deflate" (Kauahikaua et al., 1998). Cooling histories inferred from the

461 thicknesses of the upper brittle and viscoelastic layers (Hon et al., 1994) therefore

462 provide an estimate of the time that a lava pathway flowed at full capacity, but not

463 necessarily the total duration of emplacement if the core of the flow and the upper crust

464 were decoupled. In some cases, the molten core of a flow can also undergo cycles of

465 pressurization related to changes in the local discharge rate (Orr, 2011). This can lead to

466 variations in molten core pressure that induce cycles of surface disruption and

467 subsidence, thereby producing a range of surface textures that include slabbly pāhoehoe,

468 rubbly pāhoehoe, and shatter rings.

469 Initial cooling can strengthen the margins of a lava flow (Castruccio et al., 2013),

470 but the process is complicated by the development of numerous cooling fractures. These

471 fractures will mechanically weaken the outer brittle crust and make the underlying

472 viscoelastic layer more important in terms of governing the overall confining strength of

473 the flow. The frequency of breakouts will therefore depend on the balance between the

474 combined strength of the brittle and viscoelastic layers relative to the pressure within the

475 molten core (Hoblitt et al., 2012). If the internal pressure exceeds the confining strength

476 of the flow's outer layers, then the periphery of the flow will rupture and generate new

477 breakouts that promote increased areal growth. In contrast, if the exterior of the flow does

478 not rupture, it will pressurize and inflate through gradual deformation of the viscoelastic

479 layer and opening of fractures in the overlying brittle crust.

480 In this study, peripheral lobes along the margins of the PKK flow on the flanks of

481 Kīleaua Volcano, exhibited a generally constant local discharge rate $(0.0061 \pm 0.0019$

$\left.482 \mathrm{~m}^{2} / \mathrm{s}\right)$. However, approximately every four minutes there was a significant increase in the 
483 areal spreading rate. The observed periodicity in areal coverage may relate to the

484 changing balance between the confining strength of the lava as it cools and strengthens,

485 and the internal pressure within the core of the flow. This balance would give rise to an

486 increased frequency of new breakouts when the core pressure exceeds the confining

487 strength of the exterior. Enhanced areal spreading rates would then persist until the core

488 pressure decreases below a critical threshold required to continuously rupture the active

489 flow margin. As the rate of areal spreading deceases, continued influx of lava into the

490 lobe would begin to re-pressurize its fluid core and perpetuate a new cycle. This process,

491 operating on the scale of an individual lobe, is similar to what Hoblitt et al. (2012) have

492 observed on the scale of an entire pāhoehoe flow, which demonstrates the self-similarity

493 of the inflation mechanism over a range of scales.

\section{8.2. Static and Dynamic Pressure Considerations}

496 During early stages of pāhoehoe emplacement, the inflation process will be

497 dominated by molten core thickening as the liquid interior of the flow moves toward an

498 equilibrium thickness. However, there are multiple factors that can contribute to this

499 equilibrium. Calculations generally assume a Bingham liquid rheology, with lava

500 descending a slope as an unconfined laminar flow under the influence of gravity (Hulme,

501 1974; Dragoni et al., 1986; Castruccio et al., 2013). Within this scenario, the critical

502 depth $h_{s}$ required to induce down-slope flow will be

$503 \quad h_{s}=\sigma_{0} / \rho g \sin (\beta)$,

504 where $\sigma_{0}$ is the flow's yield stress, $\rho$ the flow's density, $g$ is gravitational acceleration, 505 and $\beta$ is the underlying slope (see Eq. [14] in Hulme, 1974). However, such calculations 
506 of a lava flow's equilibrium thickness will be complicated by cooling-induced changes in

507 rheology and other factors that influence its internal pressure once the molten core is

508 confined by a coherent crust. Several studies (e.g., Rossi and Gudmundsson, 1996;

509 Anderson et al., 1999, 2012) have considered the "magmastatic" pressure (herein referred

510 to as "hydrostatic" pressure) generated by fluid elevation changes along a hydrostatically

511 connected pathway, as well as the pressure required to drive lava through pipe-like

512 pathways and lift the crust. These models generally assume that the pathways (i.e., lava

513 tubes) are cylindrical pipes with constant cross-sectional area, but the geometry of lava

514 pathways can vary widely within a pāhoehoe flow (e.g., Guest et al., 1984; Kauahikaua et

515 al., 1998; Self et al., 1998; Calvari and Pinkerton, 1999). This raises the possibility that

516 changes in pathway geometry can introduce additional changes in lava core pressure due

517 to dynamic processes.

$518 \quad$ These dynamic effects may be understood within the context of Bernoulli's

519 principle, which describes the inverse relationship between fluid flow velocity and fluid

520 pressure within incompressible laminar flows through a pipe (Resnick and Halliday,

521 1977; Batchelor, 1998). For lava moving within a system of combined pathways, changes

522 in fluid core pressure could affect inflation rates by changing the magnitude of the

523 stresses applied to the overlying crust. This may lead to increased inflation rates where

524 the flow velocity decreases and the core pressure increases. Conversely, inflation rates

525 would be lower where the flow velocity increases and the core pressure decreases. For

526 otherwise equivalent lava flows through a pipe-like pathway, the most important controls

527 on fluid velocity will be the pipe's cross-sectional area and underlying slope. In general,

528 lava velocities will be relatively low where the flow pathway is broad and its cross- 
529 sectional area is large and/or where it descends a shallow slope or encounters a reverse-

530 facing slope. Alternatively, flow velocities will be higher when lava enters a narrow

531 topographic constriction and/or descends a steeper slope. These scenarios are broadly

532 consistent with the observed relationship between the initial topography and final

533 morphology for Lobe B. In this case, maximum inflation was observed where the flow

534 was the broadest and above shallow to reverse-facing slopes, whereas the least inflation

535 was observed where the flow passed through narrow constrictions and descended steep

536 slopes (Figs. 6 and 7). These observations support the viability of a conservation of

537 energy approach to modeling the spatial variability of inflation and its relationship to

538 emplacement processes. They also highlight the importance of including both fluid static

539 and dynamic components in understanding core pressure and thickening during the early

540 stages of pāhoehoe inflation. Early stage inflation processes related to core pressurization

541 and thickening may also help to establish preferred pathways through the thickest parts of

542 the flow, which would continue to preferentially inflate through crustal accretion if the

543 pathways remain full. Continued crustal accretion and uplift must also be coupled with

544 overpressurization of the molten core, which Cashman and Kauahikaua (1997) inferred

545 from their observations of pāhoehoe crustal vesicularity profiles that exhibit decreased

546 vesicle number density with depth.

\section{9. Conclusions}

549 The confining strength of a lava lobe depends strongly on the age distribution of

550 its surfaces, with the youngest surfaces (i.e., sites of the most recent breakouts) being the

551 weakest. Therefore, when new breakouts occur, growth tends to concentrate at these 
552 localities. Otherwise, the next most likely location for a breakout to occur is from an

553 older fractured surface overlying a still molten core. This process is treated with a

554 stochastic model by introducing correlation with a probability distribution describing the

555 preferential growth of the flow in the direction of new breakouts through sequential

556 emplacement of lava parcels (i.e., toes) from that locality. Including correlated growth

557 into the model also recreates observed periods of enhanced areal spreading and lobe

558 morphologies.

559 Time-series data for Lobe A shows that periods of enhanced areal spreading

560 roughly alternate with periods of increased excess volume change. For an approximately

561 constant local discharge rate, this suggests that the volume of lava not utilized during the

562 process of areal spreading can contribute to thickening through inflation. Trade-offs

563 between areal spreading and inflation should be detectable in thermal infrared (e.g.,

564 FLIR) imagery, provided that a single lobe is isolated in the field of view. For instance,

565 when the flow enters a period of above average areal spreading, newly exposed lava

566 surfaces will radiate more thermal energy and will contribute to an increased frequency

567 distribution of high temperature pixels within the field of view. As the flow shifts toward

568 an inflation-dominated mode, older lava surfaces will cool dominantly by conduction

569 rather than radiation (Hon et al., 1994), and this would shift the frequency distribution of

570 temperatures toward lower values. Temperature distributions in FLIR data may therefore

571 be used to identify patterns of pāhoehoe flow emplacement, such as periodicities in areal

572 spreading rate and the trade-off with inflation. Statistical models of flow emplacement

573 may be improved by coupling them with a cooling model to estimate the temperature

574 distribution of the lava based on its emplacement age. 
576 discharge rate flows may be deflected or stopped by obstacles measuring only a few

577 centimeters in height. This process was observed during the emplacement of Lobe B and

578 demonstrates that the final morphology of a lobe may inherit boundaries influenced by

579 variations in the initial toe-scale topography that are orders of magnitude smaller than the

580 flow's final thickness. Even though toes may be locally deflected or impeded by toe-scale

581 topography, inflating pāhoehoe lobes may overcome local barriers through a combination

582 of stochastic breakouts in down-flow and cross-flow directions that allow them to find

583 and follow the maximum regional slope. These behaviors are described in the model by

584 considering the sequential emplacement of new lava parcels (i.e., toes) from existing flow

585 margins, with boundaries that reflect parcels back towards the interior of the flow.

586 Combining measurements of initial topography with time-series observations of

587 active pāhoehoe lobes provides new insights into the growth of pāhoehoe flows. These

588 observational constraints also help to improve statistical models of lava emplacement

589 processes and better understand the relationship between areal expansion and inflation.

590 This information is important for understanding how subtle topographic influences can be

591 inherited by inflated lobes to develop preferred lava pathways that influence the overall

592 development of a flow and for interpreting the emplacement history of pāhoehoe lava

593 flows on Earth and other planetary surfaces.

\section{Acknowledgments:}

596 We thank Benjamin Brooks and the Pacific GPS facility for providing access to

597 DGPS survey equipment and post-processing resources, Samuel Hulme for his assistance 
598 with GMT, Richard Herd for kindly providing DGPS data for photogrammetry control,

599 Andy Harris for his assistance in the field making contemporaneous FLIR observations,

600 Tim Orr for providing historical lava flow data shown in Figure 1, as well as Sarah

601 Fagents, Thorvaldur Thordarson, and Jacob Bleacher for many insightful discussions

602 relating to lava flow emplacement. Prof. S. Robson and Prof. J. P. Muller are thanked for

603 their ongoing support through provision of VMS and GOTCHA, respectively. Christopher

604 Kilburn and Jim Kauahikaua are sincerely thanked for their thorough and constructive

605 reviews. Field work was conducted in Hawaii Volcanoes National Park under Scientific

606 Research and Collecting Permit \# HAVO-2006-SCI-0003. CWH was supported by an

607 appointment to the NASA Postdoctoral Program at the Goddard Space Flight Center,

608 administered by Oak Ridge Associated Universities through a contract with NASA. LSG

609 and SMB research was supported by the NASA Planetary Geology and Geophysics, and

610 Mars Data Analysis programs (LSG: 811073.02.01.04.44 and 203959.02.03.17.56; SMB:

$611 N N X 08 A F 16 G$ and $N N X 10 A P 63 G)$. 


\section{References}

613 Anderson SW, Stofan ER, Smrekar SE, Guest JE, Wood B (1999) Pulsed inflation of

614 pahoehoe lava flows: implications for flood basalt emplacement. Earth Planet Sci

$615 \quad$ Lett $168: 7-18$

616 Anderson SW, Smrekar SE, Stofan ER (2012) Tumulus development on lava flows:

617 insights from observations of active tumuli and analysis of formation models. Bull

$618 \quad$ Volcanol 74:931-946. doi:10.1007/s00445-012-0576-2

619 Baloga S (1987) Lava flows as kinematic waves. J Geophys Res 92 (B9):9271-9279

620 Baloga S, Pieri DC (1986) Time-dependent profiles of lava flows. J Geophys Res

$621 \quad 91: 9543-9552$

622 Baloga S, Glaze LS (2003) Pahoehoe transport as a correlated random walk. J Geophys

$623 \quad$ Res 108:2031. doi:10.1029/2001JB001739

624 Baloga S, Glaze LS (2008) Self-replication model for long channelized lava flows on the 625 Mars plains. J Geophys Res 113:E05003. doi:10.1029/2007JE002954

626 Batchelor GK (1980) An introduction to fluid dynamics. Cambridge Univ Press, New

$627 \quad$ York, $615 \mathrm{p}$

628 Bruno BC, Taylor GJ, Rowland SW, Baloga SM (1994) Quantifying the effect of

629 rheology of lava-flow margins using fractal geometry. Bull Volcanol 56:193-206

630 Byrnes JM, Crown DA (2001) Relationships between pahoehoe surface units,

631 topography, and lava tubes at Mauna Ulu, Kilauea Volcano, Hawaii. J Geophys

$632 \quad$ Res 106(B2):2139-2151 
633 Byrnes JM, Ramsey MS, Crown DA (2004) Surface unit characterization of the Mauna

634 Ulu flow field Kilauea Volcano, Hawai ${ }^{i}$, using integrated field and remote

635 sensing analyses. J Volcano Geothem Res 135:169-193

636 Calvari S, Pinkerton H (1999) Lava tube morphology on Etna and evidence for lava flow

637 emplacement mechanisms. J Volcanol Geotherm Res 90:263-280

638 Cashman KV, Kauahikaua JP (1997) Reevaluation of vesicle distributions in basaltic lava

639 flows. Geology 25:419-422. doi:10.1130/0091-7613

640 Castruccio A, Rust AC, Sparks RJS (2013) Evolution of crust- and core-dominated lava

641 flows using scaling analysis. Bull Volcanol 75:681. doi:10.1007/s004455-012-

$642 \quad 0681-2$

643 Crisp JA, Baloga SM (1990) A model for lava flows with two thermal components. J

$644 \quad$ Geophys Res 95:1255-1270

645 Crown DA, Baloga SM (1999) Pahoehoe toe dimensions morphology, and branching

646 relationships at Mauna Ulu, Kilauea Volcano, Hawai'i. Bull Volcanol 61:288-305

647 Danes ZF (1972) Dynamics of lava flows J Geophys Res 77:1430-1432

648 Doane DP (1976) Aesthetic frequency classifications. American Statistician 30:181-1905

649 Dragoni M, Bonafede M, Boschi E (1986) Downslope models of a Bingham liquid:

650 implications for lava flow. J Volcanol and Geotherm Res 30:305-325

651 Day T, Muller JP (1989) Digital elevation model production by stereo-matching SPOT

652 image-pairs: A comparison of algorithms. Image Vision Comp 7:95-101

653 Gruen AW (1985) Adaptive least squares correlation: A powerful image matching

654 technique. S Afr J Photogramm Remote Sens Cartogr 14:175-187

655 Glaze LS, Baloga SM (2013) Simulation of inflated pahoehoe lava flows. J 
657 Guest JE, Wood C, Greeley R (1984) Lava tubes, terraces and megatumuli on the 1614-

65824 pahoehoe lava flow field, Mount Etna, Sicily. Bull Volcanol 47(3):635-648

659 Hamilton CW, Thordarson T, Fagents SA (2010) Explosive lava-water interactions I:

660 architecture and emplacement chronology of volcanic rootless cone groups in the

661 1783-1784 Laki lava flow, Iceland. Bull Volcanol 72(4):449-467.

662 doi:10.1007/s00445-009-0330-6.

663 Harris AJL, Rowland SK (2001) FLOWGO: A kinematic thermo-rheological model for 664 lava flowing in a channel. Bull Volcanol 63:20-44

665 Harris AL, Dehn J, James MR, Hamilton C, Herd R, Lodato L, Steffke A(2007a)

666 Pahoehoe flow cooling, discharge, and coverage rates from thermal image

667 chronometry. Geophys Res Lett 34:L19303. doi:10.1029/2007GL030791

668 Harris AJL, Dehn J, Calvari S(2007b) Lava effusion rate definition and measurement: a 669 review. Bull Volcanol 70:1-22

670 Harris AJL (2013) Lava flows. In: Modeling volcanic processes: the physics and mathematics of volcanism (eds. S.A. Fagents, T.K.P. Gregg, and R.M.C. Lopes).

673 Hon K, Kauahikaua J, Denlinger R, MacKay R (1994) Emplacement and inflation of pahehoe sheet flows: Observations and measurements of active lava flows on

676 Hoblitt RP, Orr TR, Heliker C, Denlinger RP, Hon K, Cervelli PF (2012) Inflation rates, 677 rifts, and bands in a pāhoehoe sheet flow. Geosphere 8(5):179-195.

$678 \quad$ doi: $10.1130 /$ GES00656.1 
679 Hulme G (1974) The interpretation of lava flow morphology, Geophys J R astr Soc

$680 \quad 39: 361-383$

681 Kauahikaua J, Cashman KV, Mattox TN, Heliker CC, Hon LA, Mangan MT, Thornber 682 CR (1998) Observations on basaltic lava streams in tubes from Kilauea Volcano, 683 island of Hawai'i. J Geophys Res 103(B11):27,303-27,323

684 Keszthelyi L, Denlinger R (1996) The initial cooling of pahoehoe flow lobes. Bull $685 \quad$ Volcanol 58:5-18

686 Keszthelyi L, Self S, Thordarson T (1999) Application of recent studies on the 687 emplacement of basaltic lava flows to the Deccan Traps, Memoirs - Geolog Soc $688 \quad$ India $43: 485-520$

689 Keszthelyi L, Self S, Thordarson T (2006) Flood lavas on Earth, Io and Mars. J Geol Soc 690 163(2):253-264

691 Keszthelyi L, McEwen AS, Thordarson T (2000) Terrestrial analogs and thermal models 692 for Martian flood lavas. J Geophys Res 105(E6):15,027-15,049

693 Kilburn CRJ (1996) Patterns and predictability in the emplacement of subaerial lava 694 flows and flow fields. In: Scarpa R., R.I. Tilling (eds.) Monitoring and mitigation 695 of volcanic hazards. Springer, New York: pp 491-537

696 Koeppen WC, Patrick M, Orr T, Sutton AJ, Dow D, Wright R (2013) Constraints on the 697 portioning of Kīlauea's lavas between surface and tube flows, estimated from 698 infrared satellite data, sulfur dioxide emission rates, and field observations. Bull $699 \quad$ Volcanol 75:716. doi:10.1007/s00445-013-0716-3 
Orr TR (2011) Lava tube shatter rings and their correlation with lava flux increases at Kīlauea Volcano, Hawai ‘i. Bull Volcanol 73:355-346. doi:10.1007/s00445-0100414-3

703

704

705

706

707

708

709

710

711

712

713

714

715

716

717

718

719

720

721

722

Otto GP, Chau TKW (1989) Region-growing algorithm for matching of terrain images, Image Vision Comp 7:83-94

Peitersen MN, Crown DA (2000) Correlations between topography and intraflow width behavior in Martian and terrestrial lava flows. J Geophys Res 105(E2):4123-4123

Poland MP, Miklius A, Jeff Sutton A, Thornber CR (2012) A mantle-driven surge in magma supply to Kilauea Volcano during 2003-2007. Nature Geosci 5(4):295300

Ramsey MS, Harris AJL (2012) Volcanology 2010: How will thermal remote sensing of volcanic surface activity evolve over the next decade? J Volcanol Geotherm Res. $249: 217-233$

Resnick R, Halliday D (1977) Physics: Part One ( $3^{\text {rd }}$ ed.). John Wiley \& Sons, New York, $608 \mathrm{p}$

Robson S, James MR (2007) Photogrammetric image sequence processing to determine change in active lava flows. Proc Remote Sensing and Photogrammetry Society Ann Conf, 2007 (RSPSoc 2007), 11-14th September, Newcastle upon Tyne, U.K.

Rossi MJ, Gudmundsson A (1996) The morphology and formation of flow-lobe tumuli and Icelandic shield volcanoes. J Volc Geotherm Res 72:291-308

Rowland SK, Harris AJL, Garbeil H (2004) Effects of martian conditions on numerically modeled, cooling-limited channelized lava flows. J Geophys Res 109(E10010). doi:10.1029/2004JE002288 
723 Self S, Thordarson T, Keszthelyi L, Walker GPL, Hon K, Murphy MT, Long P,

724 Finnemore D (1996) A new model for the emplacement of Columbia River

725 basalts as large, inflated pahoehoe lava flow fields. Geophys Res Lett 23:2689-

$726 \quad 2692$

727 Self S, Keszthelyi L, Thordarson T (1998) The importance of pāhoehoe. Ann Rev Earth

$728 \quad$ Planet Sci 26(1):81-110

729 Smith WHF, Wessel P (1990) Gridding with continuous curvature splines in tension.

$730 \quad$ Geophysics 55(3):293-305

731 Sturges H (1926) The choice of a class-interval. J Amer Statist Assoc 21:65-66

732 Thordarson T, Self S (1998) The Roza Member, Columbia River Basalt Group: A

733 gigantic pahoehoe lava flow field formed by endogenous processes? J Geophys

$734 \quad$ Res 103(B11):27411-27445

735 Walker GPL (1991) Structure, and origin by injection of lava under surface crust, of

736 tumuli, 'lava rises', 'lava-rise pits', and 'lava-inflation clefts' in Hawaii. Bull

$737 \quad$ Volcanol 53:546-558

738 Walker GPL (2009) The endogenous growth of pahoehoe lava lobes and morphology of

739 lava-rise edges. In: Thordarson T, Self S, Larsen G, Rowland SK, Hoskuldsson A

740 (eds) Studies in volcanology — the legacy of George Walker (Special Publications

741 of IAVCEI No. 2). The Geol Soc: pp 17-32

742 Wilmoth RA, Walker GPL (1993) P-type and S-type pahoehoe: a study of vesicle

743 distribution and patterns in Hawaiian lava flows. J Volcanol Geotherm Res

$744 \quad 55: 129-142$ 


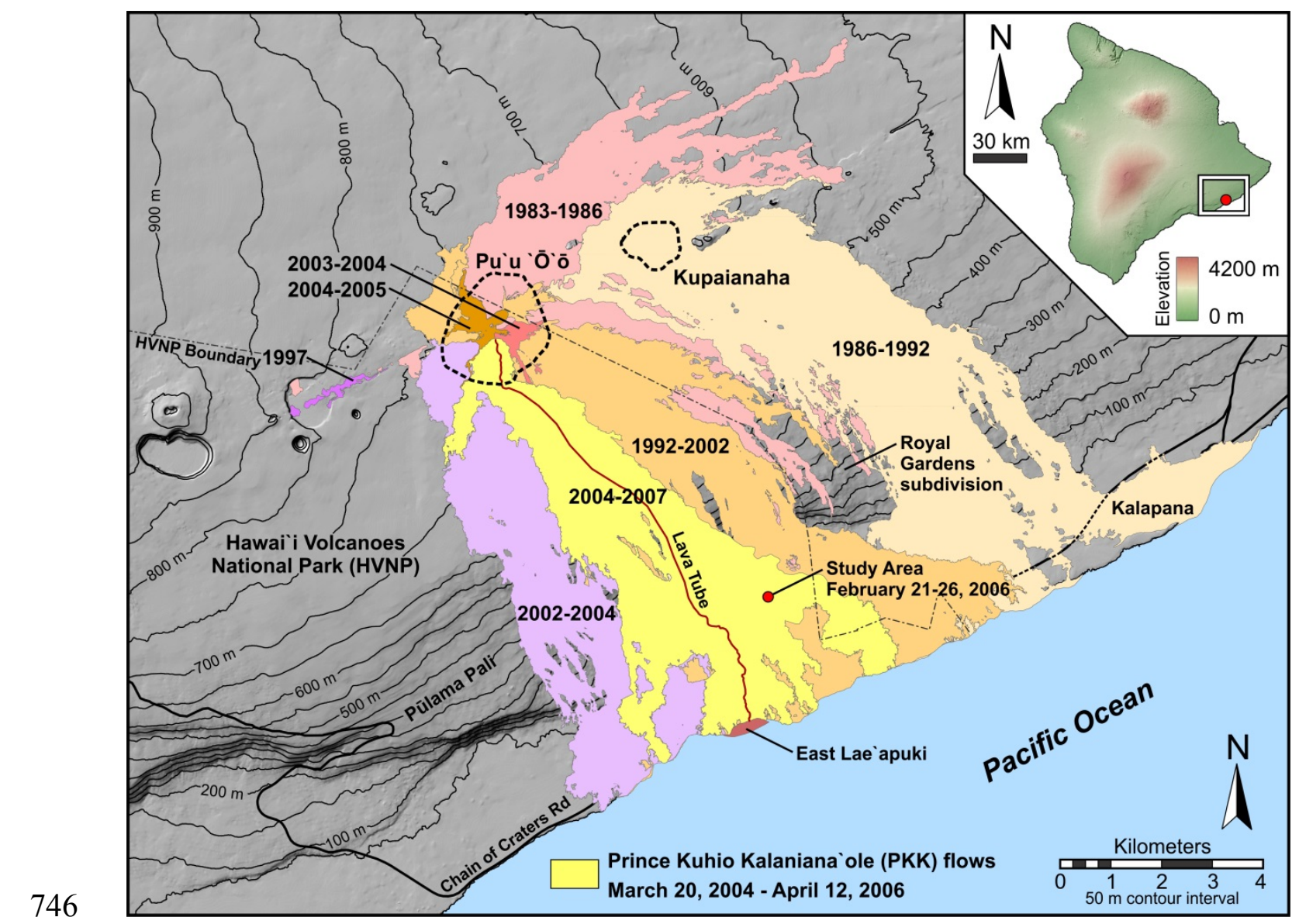

747 Figure 1. Lava flow map showing the study area location $\left(19.336430^{\circ} \mathrm{N},-\right.$

$748155.055235^{\circ} \mathrm{W}$ ) within the Prince Kūhiō Kalaniana' ole (PKK) flow (shown in yellow) on

749 Kīlauea Volcano, Hawai 'i. Pāhoehoe lava lobes at this locality were fed lava from $\mathrm{Pu}^{\text {‘u }} \mathrm{u}$

750 ' $\overline{\mathrm{O}}^{`} \overline{\mathrm{o}}$. Field measurements were acquired on 21-26 February 2006 for two lobes (A and

751 B) located along the same lava pathway system. Lobe B was located directly down-slope

752 of Lobe A, with a separation distance of $\sim 10 \mathrm{~m}$. The dashed lines approximately bound

753 the edifices of $\mathrm{Pu}^{‘} \mathrm{u}$ ' ${ }^{`}{ }^{`} \mathrm{o}$ and Kupaianaha. Lava flow data provided by Tim Orr, United

754 States Geologic Survey (USGS). 


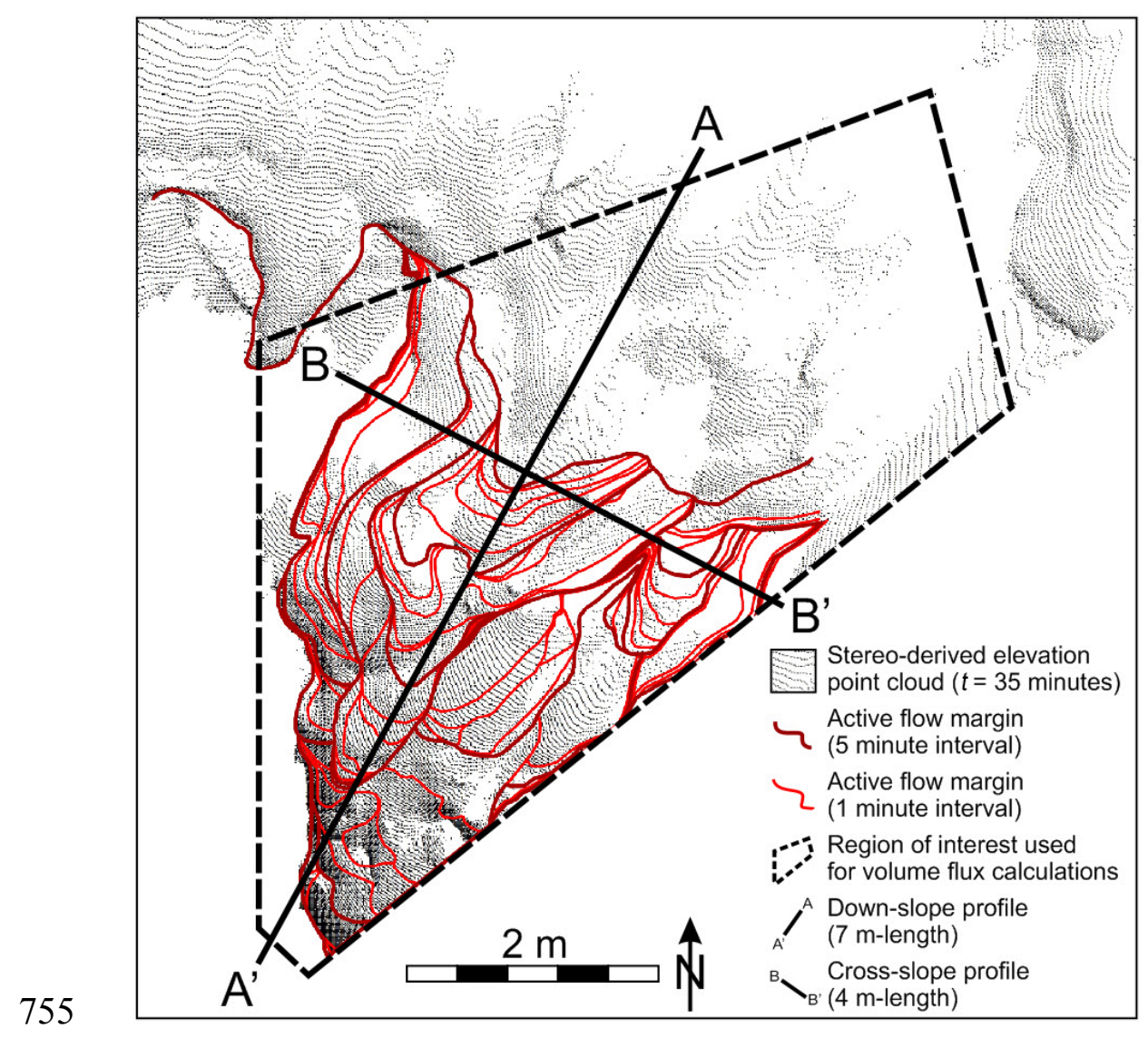

756 Figure 2. Orthorectified view of photogrammetric point cloud at time $t=35$ minutes for

757 Lobe A, with overlaid lava flow boundaries shown at 1 minute intervals and the locations

758 of the down-slope $\left(\overline{A A^{\prime}}\right)$ and cross-slope $\left(\overline{B B^{\prime}}\right)$ profiles shown in Figure 4. 


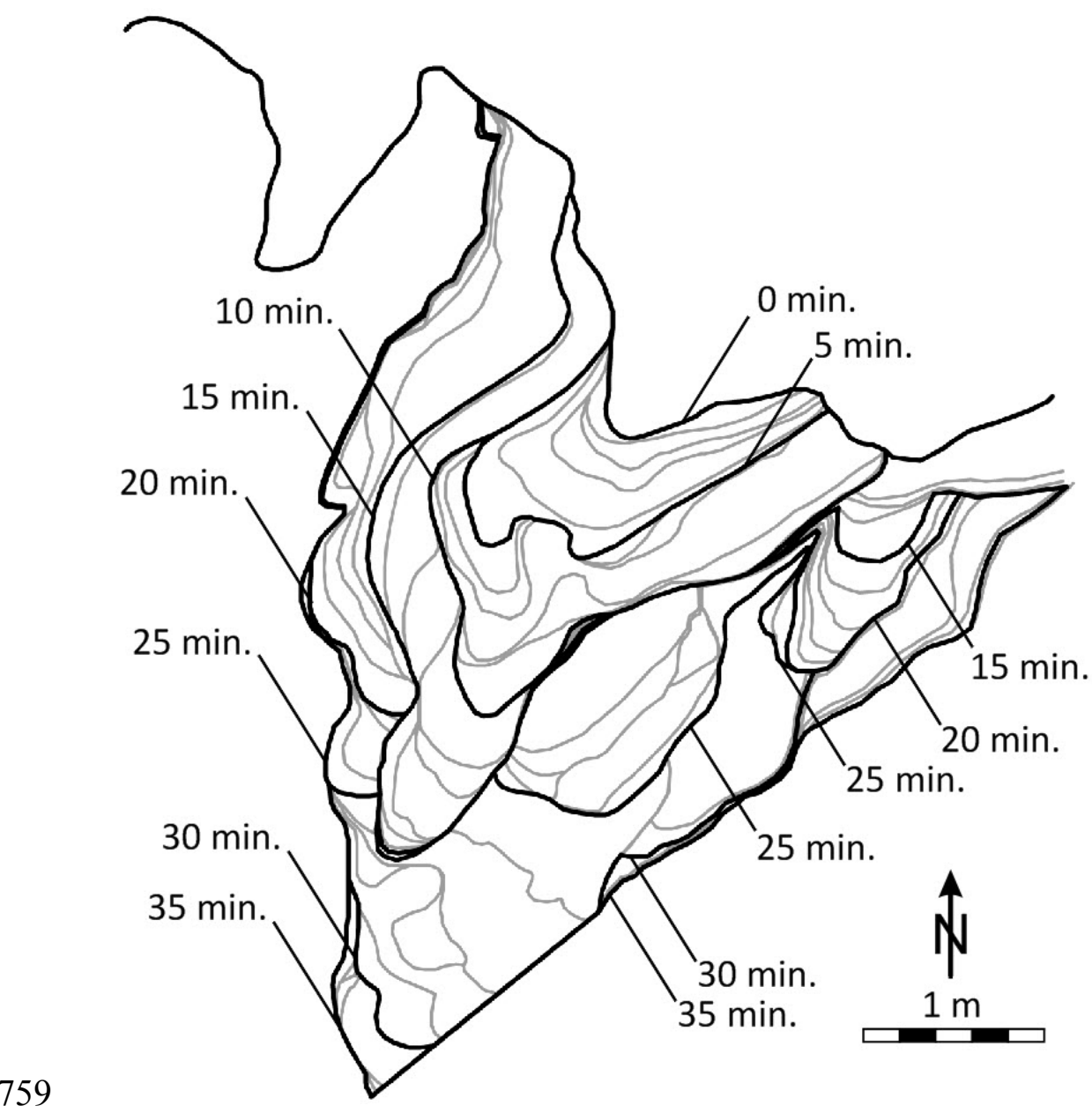

760 Figure 3. Time series evolution of Lobe A. Dark lines show the extent of the flow at 5

761 minute intervals with grey lines showing the flow margins at 1 minute intervals. The flow

762 begins to move outside the field of view at 28 minutes. 

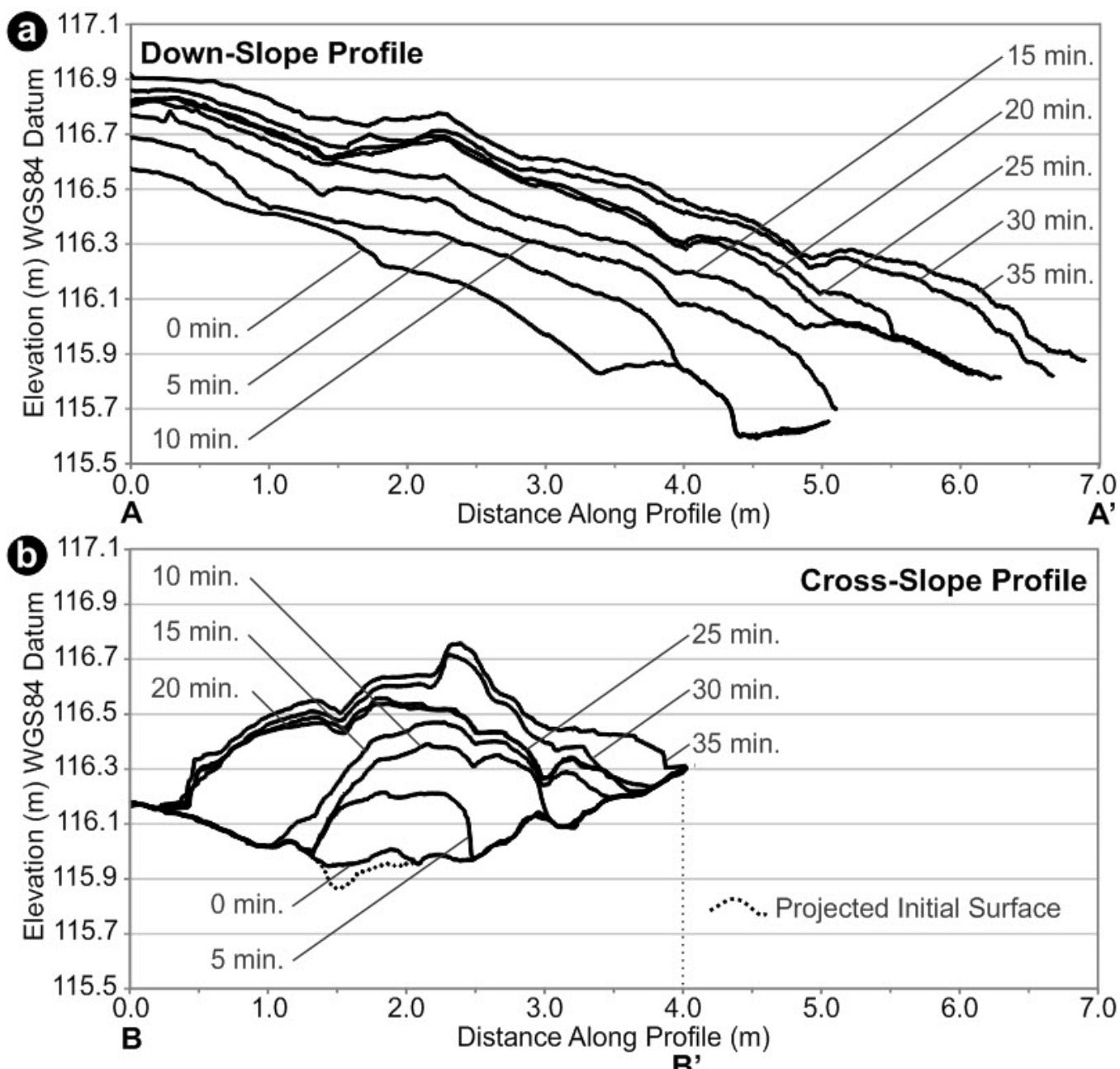

764 Figure 4. (a) Down-slope $\left(\overline{A A^{\prime}}\right)$ and (b) cross-slope $\left(\overline{B B^{\prime}}\right)$ profiles for Lobe A showing

765 the changing topography of the lava lobe shown in Figures 1 and 2. 

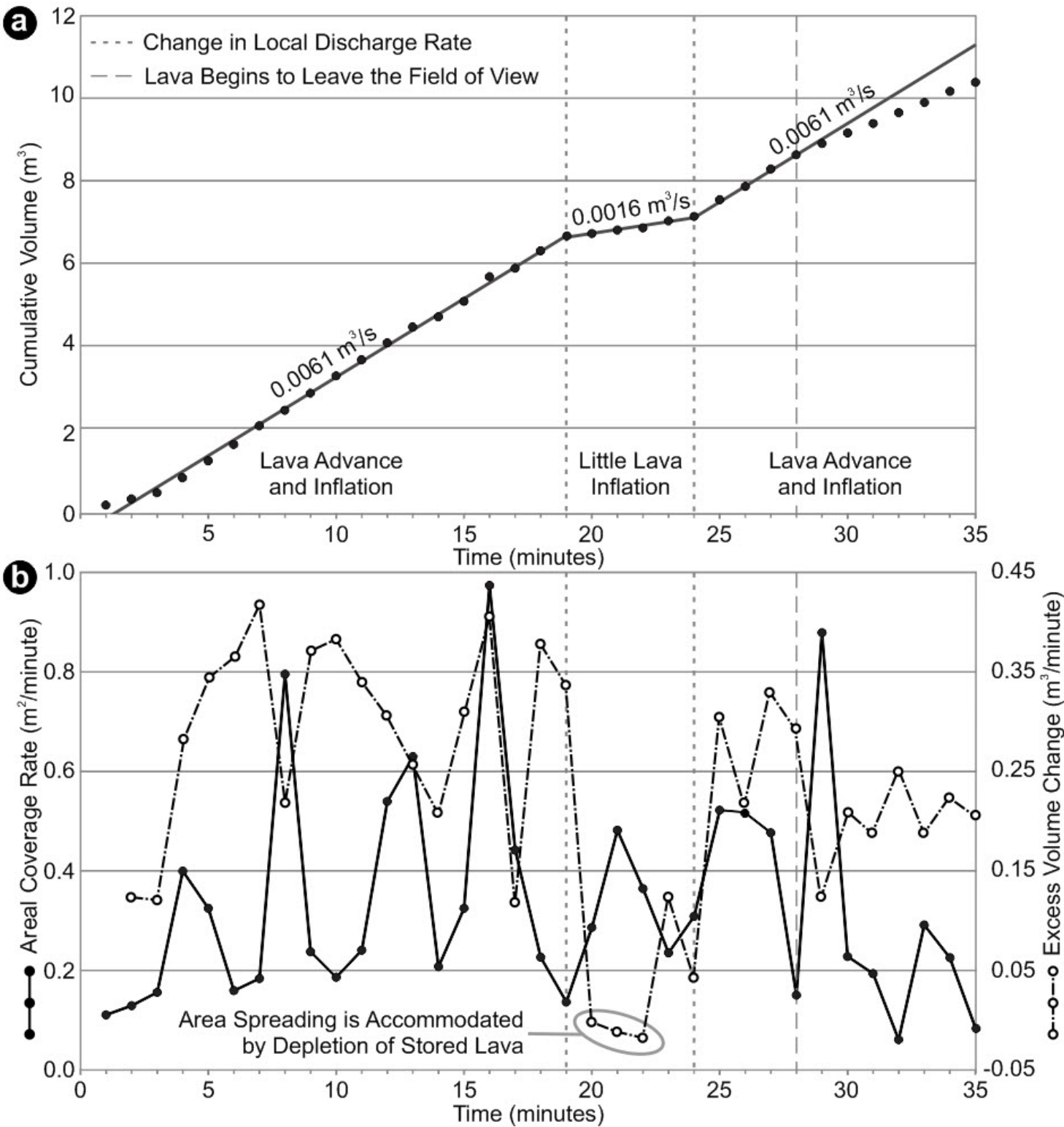

767 Figure 5. (a) Cumulative volume in the region of interest identified in Figure 2 for Lobe

768 A. The mean local discharge rate $\left(0.0061 \pm 0.0019 \mathrm{~m}^{3} \mathrm{~s}^{-1}\right.$, calculated for the first 19

769 minutes) is generally constant during the observation period, except for the interval

770 between 19 and 24 minutes where the mean local discharge rate decreases by nearly a

771 factor of four and the lobe experiences little inflation and generally lower than average

772 areal spreading rates. At 28 minutes, the rate of volume change gradually decreases as the

773 active flow front begins to exit the field of view of the stereo-cameras. (b) Areal coverage 
774 rate (mean $0.33 \pm 0.23 \mathrm{~m}^{2} /$ minute, filled black circles with solid black line) and mean

775 excess volume change $\left(0.23 \pm 0.12 \mathrm{~m}^{3} /\right.$ minute, open circles with broken line $)$, where

776 excess volume change is defined in the text. Excess volume changes less than zero,

777 between 20-23 minutes, implies that areal growth was accommodated by depletion of

778 stored lava during this time interval. The areal coverage rate shows a periodicity with

779 peaks at intervals of $4.13 \pm 0.64$ minutes. All uncertainties are reported at $1 \sigma$. 


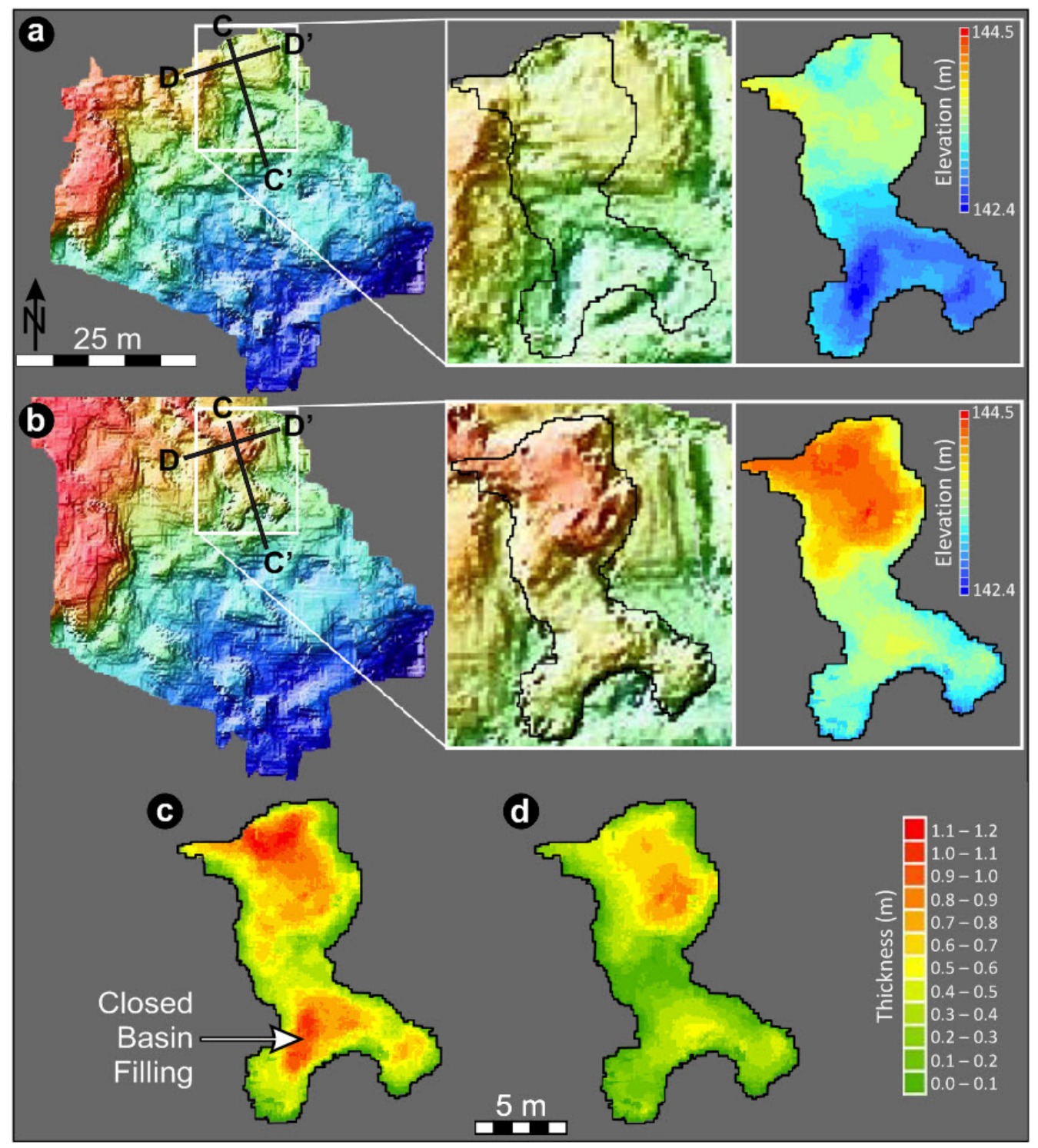

781 Figure 6. (a) Initial and (b) post-lava lobe emplacement digital terrain models (DTMs)

782 generated from Differential Global Positioning System (DGPS) measurements for Lobe

783 B, with cool colors showing low elevation and warm colors showing relatively higher

784 elevation. (c) Simple difference between the final and initial topography. (d) Difference

785 between the final topography and a Laplacian harmonic surface solution, which removes

786 the effects of closed basin filling. Profiles $\overline{C C^{\prime}}$ and $\overline{D D^{\prime}}$ are shown in Figures $7 \mathrm{a}$ and $7 \mathrm{~b}$,

787 respectively. Elevations in (a) and (b) are reported relative to the WGS84 datum, and lava

788 thicknesses in (c) and (d) are shown to the same scale. 

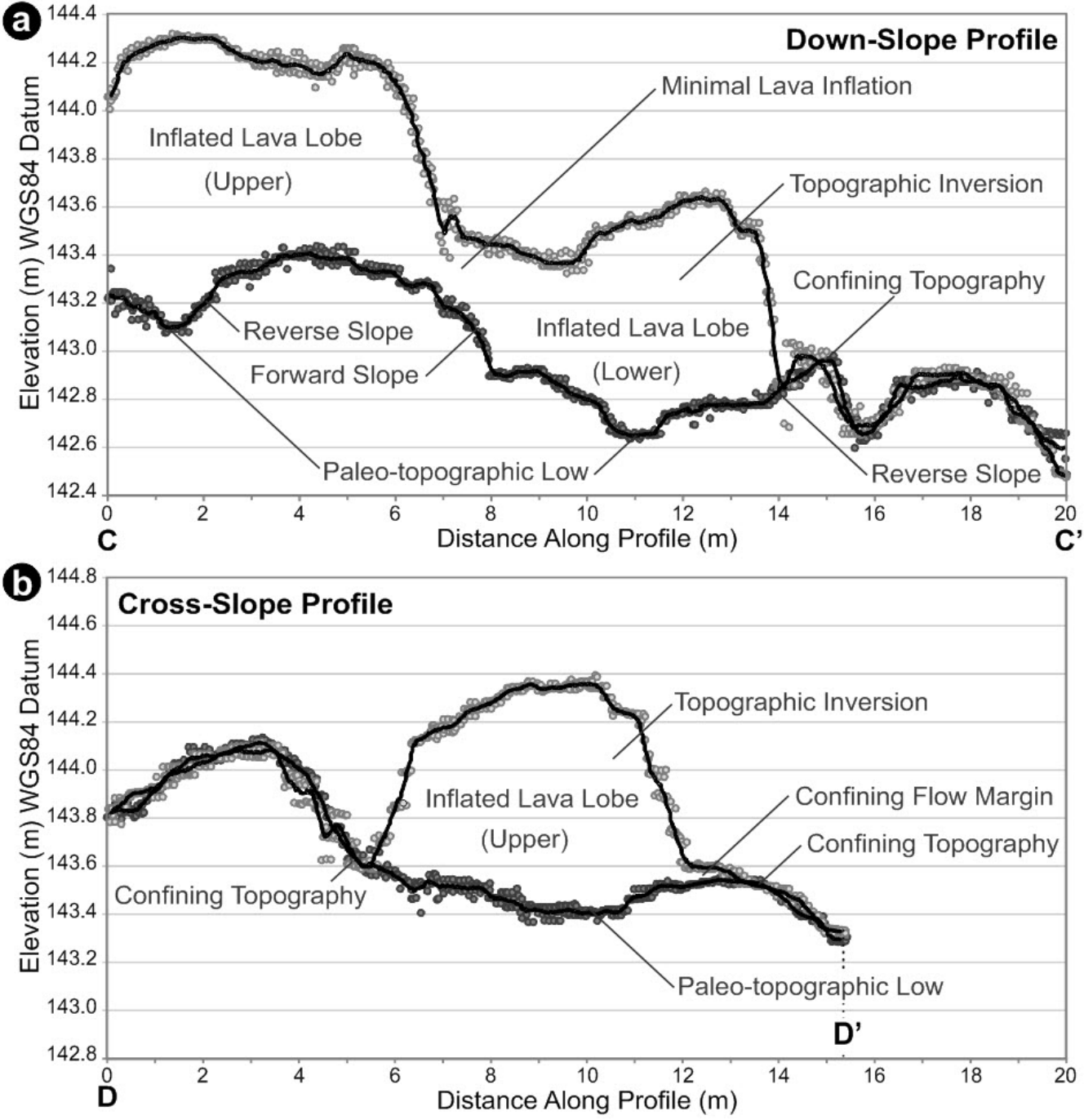

790 Figure 7. (a) Down-slope and (b) cross-slope profiles showing the initial and final

791 topography for Lobe $\mathrm{B}$ (see $\overline{C C^{\prime}}$ and $\overline{D D^{\prime}}$ in Figure 6). The flow has topographically

792 inverted the landscape, with inflation being greatest above paleo-topographic lows and

793 anti-facing slopes, and least above forward-facing slopes. Note the pre-eruption

794 topography and thin confining flow margins that may help to confine the thicker interior

795 portions of the lobe. 


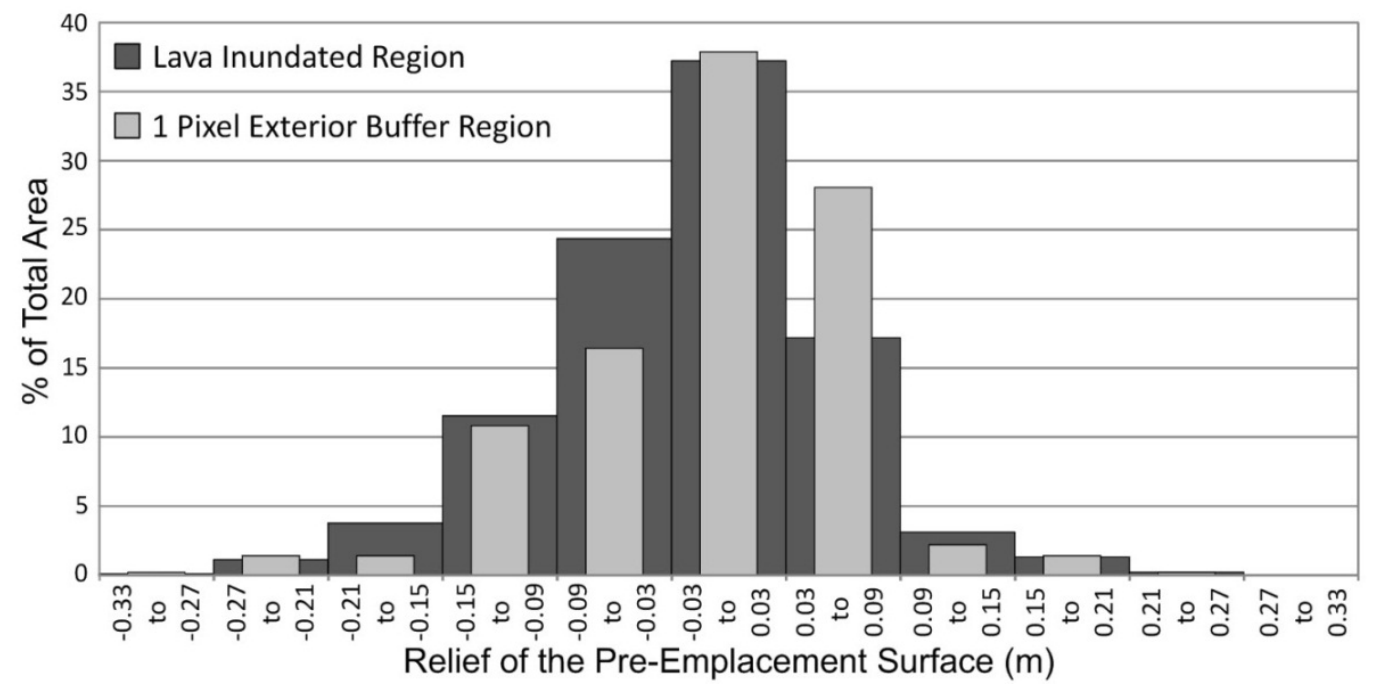

Relief of the Pre-Emplacement Surface $(\mathrm{m})$

797 Figure 8. Frequency distribution of relief on initial surface within the lava inundated

798 region (dark grey) and within a 1 pixel buffer region around Lobe B (light grey). The

799 mean relief within both regions is close to zero (i.e., $0.02 \pm 0.07 \mathrm{~m}$ in the inundated

800 region and $0.00 \pm 0.07 \mathrm{~m}$ in the buffer region), but the buffer region exhibits more +0.03

801 to $+0.09 \mathrm{~m}$ relief surfaces and -0.09 to $-0.03 \mathrm{~m}$ relief surface, which implies that positive

802 relief on the order of only a few centimeters may act to confine the areal spreading of the

803 flow. All uncertainties are reported at $1 \sigma$. 

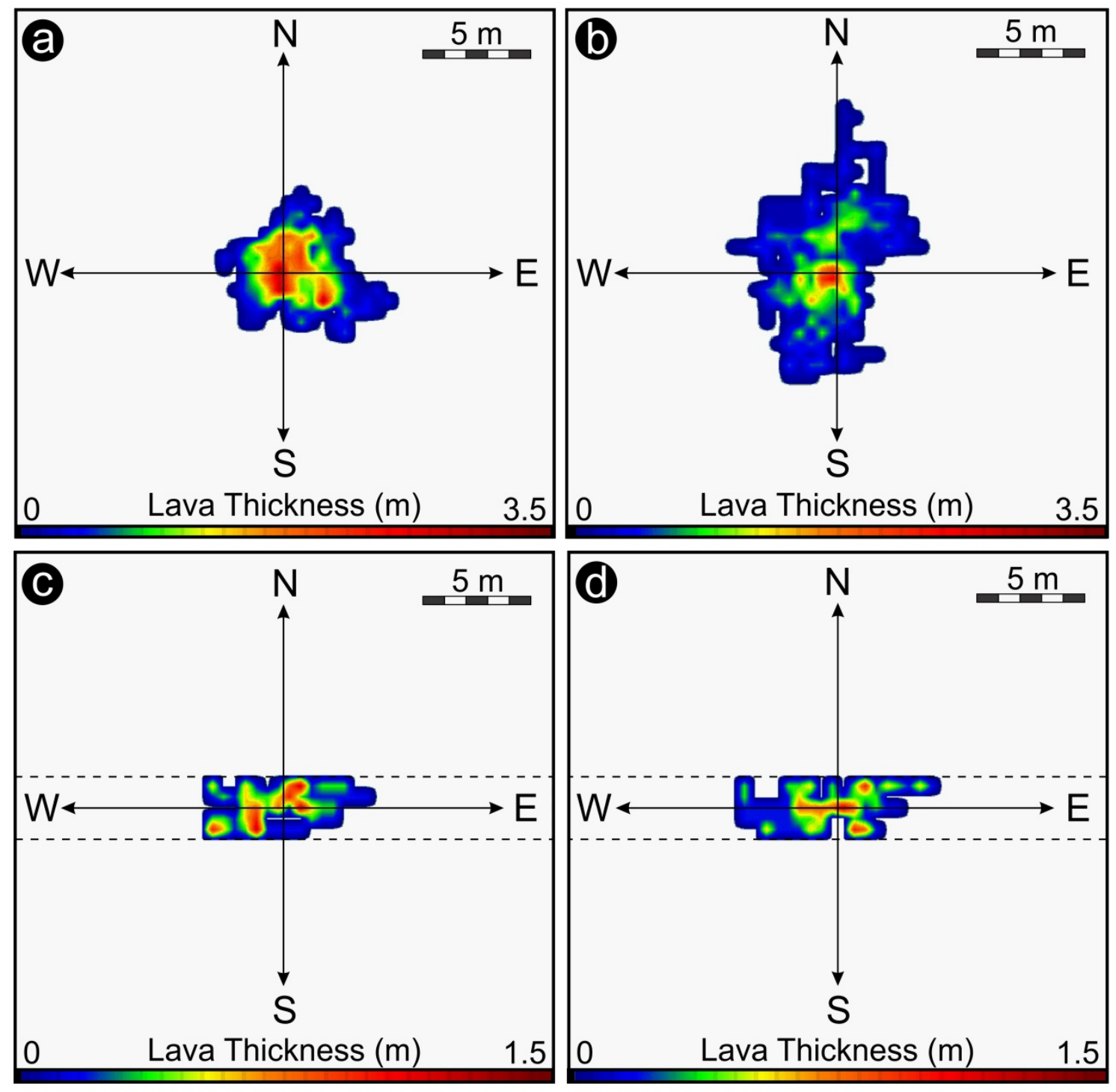

805 Figure 9. (a) Simulation of 500 randomly emplacement lava parcels (without

806 sequential breakouts from lobe margins). The maximum flow thickness is $3.2 \mathrm{~m}$. (b)

807 Simulation of 500 lava parcels using the same probability distribution for correlated toe

808 growth used to model Lobe A (i.e., $P(0)=P(1)=0.25$ and $P(2)=0.5$ ). The maximum

809 flow thickness is $2.6 \mathrm{~m}$. Note that including correlated breakouts in (b) increases the

810 perimeter:area ratio relative to the random example shown in (a). (c and d) Plan view

811 examples of two simulations of Lobe A using 117 lava parcels, boundaries (dash lines) at

$812 \pm 3$ cells on the North-South axis, and a probability distribution of $P(0)=P(1)=0.25$ and 
$813 P(2)=0.5$ for adding 0,1 , and 2 extra parcels in the same direction when a parcel breaks

814 out from the flow margin. The maximum height of the flows shown in (c) and (d) are 1.2

$815 \mathrm{~m}$. For visualization purposes, the REBIN function in Interactive Data Language (IDL)

816 was used to magnify the cells by a factor of 10 and perform a default bilinear

817 interpolation. This process smoothes the model output and provides the exterior toes with

818 a rounded appearance. This process does not alter the raw model output shown in Figures

81910 or $11 b$. 

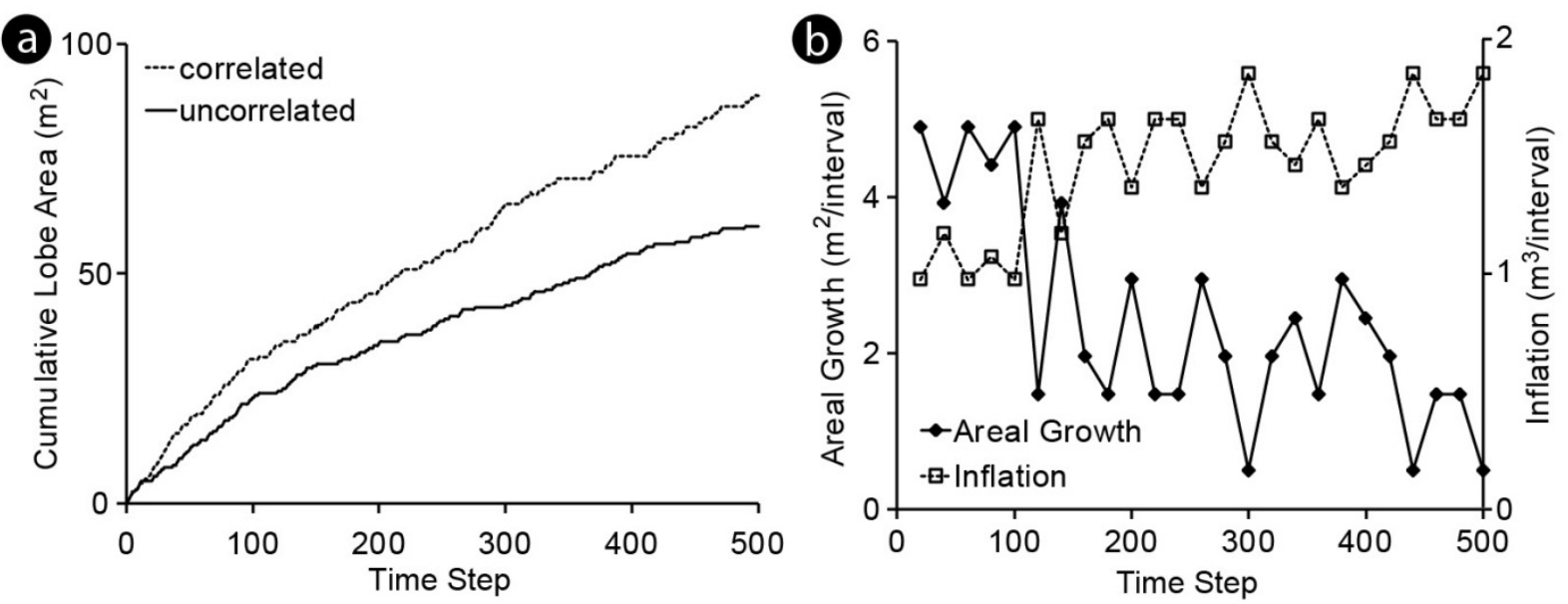

821 Figure 10. (a) Cumulative lobe area versus time for two stochastic simulation realizations

822 of pāhoehoe lobe emplacement. The uncorrelated realization (lower solid line) was

823 generated by considering purely random selection of both the location and direction of

824 each parcel transfer. The correlated scenario (upper dashed line) modifies this model by

825 introducing an increased probability of sequential parcel emplacement when new parcels

826 break out at the periphery of the flow. In this case, the probabilities of adding 0,1 , and 2 ,

827 correlated parcels are $P(0)=0.25, P(1)=0.25$, and $P(2)=0.5$, respectively. (b) Shows

828 the periodicities and anti-correlation in areal spreading and excess volume change for a

829 typical purely random simulation and an interval of 20 time steps.

830 

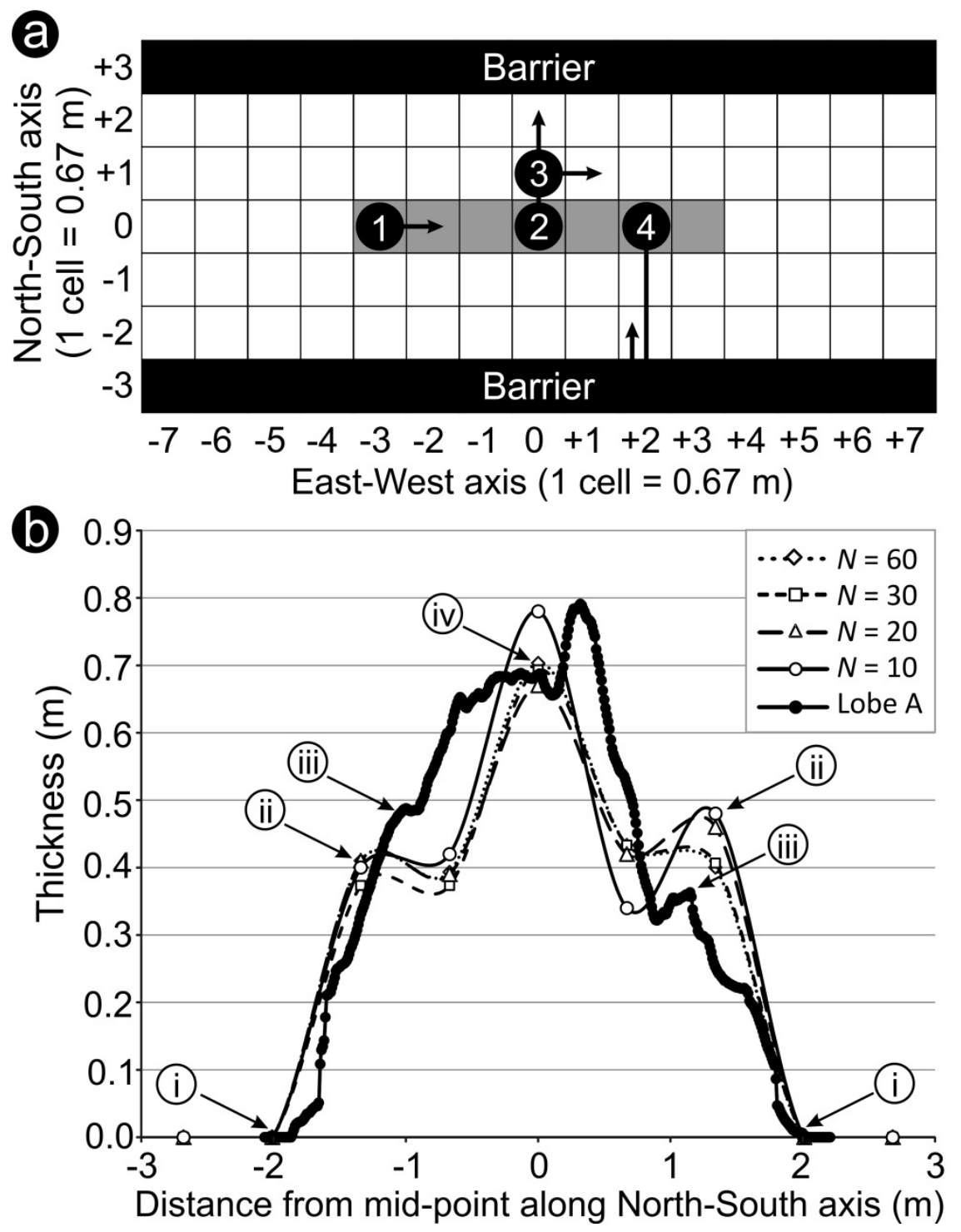

832 Figure 9. (a) A schematic example showing how the stochastic model works. A linear

833 source region (shown in gray) passes through the mid-point of the array and trends East-

834 West. Two parallel barriers are shown \pm 3 cells from the linear source along the North-

835 South axis. In the simulation, a cell is first chosen at random from within the confines of

836 the flow (initially corresponding to the extent of the linear source region) and then a

837 random cardinal direction is chosen. A lava parcel is then transferred to the specified cell

838 (marked with a filled black circle, e.g., "1") and to adjacent cell (identified by the

839 associated arrow). If the parcel would be allocated beyond the confines of the flow, there 
840 is a $0.25,0.25$, and 0.50 probability that 0,1 , or 2 extra parcels, respectively, will be

841 allocated to sequential cells in the same direction (e.g., "2" shows 1 extra, 2 total, cells

842 being added). As the areal extent of the flow increases, new parcel transfer locations

843 become available (e.g., "3”). If a cell allocation would result in a parcel being extended

844 beyond the barrier, then the parcel is reflected back towards the cell interior (e.g., "4”).

845 Each parcel allocated to a given cell increases its thickness by $0.2 \mathrm{~m}$. This process is

846 repeated until all lava parcels are allocated, which in the case of Lobe A, includes a total

847 of 117 parcels. (b) Simulated North-South profiles for Lobe A, averaged over 10, 20, 30,

848 and 40 realizations of the model. The results show that despite the stochastic nature of the

849 model, the average simulations converge to a stable equilibrium shape over a few tens of

850 realizations. Also shown is the flow-perpendicular cross-section though Lobe A (Fig. 4b)

851 with the underlying topographic trend removed. "i": The maximum width simulated lobes

852 and Lobe A are determined by the influences of topographic barriers. "ii": Reflecting of

853 lava parcels by the barriers produces an excess thickening in the adjacent interior cells.

854 "iii": High-standing topography and stagnated peripheral toes helps to confine the interior

855 of the lobe and promote inflation. "iv": The thickest portion of the simulated lobe is

856 located along the medial axis and is generally consistent with the thickness of Lobe A

857 along the flow axis. 